\title{
The Biological Basis of Chronic Traumatic Encephalopathy following Blast Injury: A Literature Review
}

\author{
*Matt Aldag, Regina C. Armstrong, ${ }^{2}$ Faris Bandak, ${ }^{3}$ Patrick S.F. Bellgowan, Timothy Bentley, \\ Sean Biggerstaff, Katrina Caravelli, Joan Cmarik, Alicia Crowder, Thomas J. DeGraba, \\ Travis A. Dittmer, ${ }^{1}$ Richard G. Ellenbogen, ${ }^{10}$ Colin Greene, ${ }^{11}$ Raj K. Gupta, ${ }^{12}$ Ramona Hicks, ${ }^{13}$ \\ Stuart Hoffman, ${ }^{14}$ Robert C. Latta III, ${ }^{15}$ Michael J. Leggieri Jr, ${ }^{12}$ Donald Marion, ${ }^{16}$ Robert Mazzoli, ${ }^{17}$ \\ Michael McCrea, ${ }^{18}$ John O'Donnell, ${ }^{19}$ Mark Packer, ${ }^{20}$ James B. Petro, ${ }^{21}$ Todd E. Rasmussen, \\ Wendy Sammons-Jackson, ${ }^{22}$ Richard Shoge, ${ }^{23}$ Victoria Tepe, ${ }^{20}$ Ladd A. Tremaine, ${ }^{24}$ and James Zheng ${ }^{25}$
}

\begin{abstract}
The United States Department of Defense Blast Injury Research Program Coordinating Office organized the 2015 International State-of-the-Science meeting to explore links between blast-related head injury and the development of chronic traumatic encephalopathy (CTE). Before the meeting, the planning committee examined articles published between 2005 and October 2015 and prepared this literature review, which summarized broadly CTE research and addressed questions about the pathophysiological basis of CTE and its relationship to blast- and nonblast-related head injury. It served to inform participants objectively and help focus meeting discussion on identifying knowledge gaps and priority research areas. CTE is described generally as a progressive neurodegenerative disorder affecting persons exposed to head injury. Affected individuals have been participants primarily in contact sports and military personnel, some of whom were exposed to blast. The symptomatology of CTE overlaps with Alzheimer's disease and includes neurological and cognitive deficits, psychiatric and behavioral problems, and dementia. There are no validated diagnostic criteria, and neuropathological evidence of CTE has come exclusively from autopsy examination of subjects with histories of exposure to head injury. The perivascular accumulation of hyperphosphorylated tau (p-tau) at the depths of cortical sulci is thought to be
\end{abstract}

\footnotetext{
${ }^{1}$ Booz Allen Hamilton, McLean, Virginia.

${ }^{2}$ Uniformed Services University of the Health Sciences, Bethesda, Maryland.

${ }^{3}$ Defense Advanced Research Projects Agency, Arlington, Virginia.

${ }^{4}$ National Institute of Neurological Disorders and Stroke, Bethesda, Maryland.

${ }^{5}$ Office of Naval Research, Arlington, Virginia.

${ }^{6}$ Office of the Assistant Secretary of Defense, Health Affairs, Falls Church, Virginia.

${ }^{7}$ Office of the Principal Assistant for Acquisition, United States Army Medical Research and Materiel Command, Frederick, Maryland.

${ }^{8}$ Combat Casualty Care Research Program, United States Army Medical Research and Materiel Command, Fort Detrick, Maryland.

${ }^{9}$ National Intrepid Center of Excellence, Bethesda, Maryland.

${ }^{10}$ Departments of Neurological Surgery and Global Health Medicine, University of Washington, Seattle, Washington.

${ }^{11}$ Joint Trauma Analysis and Prevention of Injuries in Combat Program, Frederick, Maryland.

${ }^{12}$ Department of Defense Blast Injury Research Program Coordinating Office, United States Army Medical Research and Materiel Command, Frederick, Maryland.

${ }^{13}$ One Mind, Seattle, Washington.

${ }^{14}$ Department of Veterans Affairs, Washington, D.C.

${ }^{15}$ United States Air Force, Dayton, Ohio.

${ }^{16}$ Defense and Veterans Brain Injury Center, Silver Spring, Maryland.

${ }^{17}$ Vision Center of Excellence, Bethesda, Maryland.

${ }^{18}$ Medical College of Wisconsin, Milwaukee, Wisconsin.

${ }^{19}$ Marine Corps Systems Command, Quantico, Virginia.

${ }^{20}$ Hearing Center of Excellence, Lackland, Texas.

${ }^{21}$ Office of the Assistant Secretary of Defense, Research and Engineering, Arlington, Virginia.

${ }^{22}$ Office of the Principal Assistant for Research and Technology, United States Army Medical Research and Materiel Command, Fort Detrick, Maryland.

${ }^{23}$ Military Operational Medicine Research Program, United States Army Medical Research and Materiel Command, Fort Detrick, Maryland.

${ }^{24}$ Armed Forces Medical Examiner Systems, Dover, Delaware.

${ }^{25}$ Program Executive Office Soldier, Fort Belvoir, Virginia.

*Authors are listed alphabetically.
} 
unique to CTE and has been proposed as a diagnostic requirement, although the contribution of p-tau and other reported pathologies to the development of clinical symptoms of CTE are unknown. The literature on CTE is limited and is focused predominantly on head injuries unrelated to blast exposure (e.g., football players and boxers). In addition, comparative analyses of clinical case reports has been challenging because of small case numbers, selection biases, methodological differences, and lack of matched controls, particularly for blast-exposed individuals. Consequently, the existing literature is not sufficient to determine whether the development of CTE is associated with head injury frequency (e.g., single vs. multiple exposures) or head injury type (e.g., impact, nonimpact, blast-related). Moreover, the incidence and prevalence of CTE in at-risk populations is unknown. Future research priorities should include identifying additional risk factors, pursuing population-based longitudinal studies, and developing the ability to detect and diagnose CTE in living persons using validated criteria.

Keywords: blast injury; chronic traumatic encephalopathy; neurodegeneration; repetitive head trauma; traumatic brain injury

\section{Introduction}

$\mathbf{T}$ The notion that Chronic neurodegeneration may follow head injury was introduced in 1928 by Harrison Martland ${ }^{1}$ in his clinical descriptions of former boxers who exhibited a range of neuropsychiatric and motor symptoms known as "punch drunk syndrome." In the following years, the hypothesized link between head injury and development of a distinctive neurodegenerative disease gained support from additional clinical case reports and eventually from histopathological assessments of affected brains. The term "chronic traumatic encephalopathy" (CTE) was coined in $1957^{2}$ but did not achieve wide recognition until its revival in 2005 when Omalu and colleagues ${ }^{3}$ used CTE to describe a progressive tauopathy affecting the post-mortem brains of professional American football players. In the intervening decade, clinical and behavioral evidence of CTE has been reported in a diverse group of persons that includes service members, domestic abuse victims, and contact sport athletes.

More than 300,000 service members and veterans have sustained at least one blast- and/or impact-related traumatic brain injury (TBI) because of the widespread use of conventional and improvised explosive devices (IED) in the conflicts in Iraq and Afghanistan. ${ }^{4}$ After the initial symptoms resolve, approximately $10-15 \%$ of individuals continue to report persistent cognitive and postconcussive symptoms. The long-term impact of blast- and impactrelated TBI is largely unknown, including whether chronic symptoms are associated with clinically detectable alterations in brain structure and function. There is growing concern that persons with a history of head injury, with or without a diagnosis of TBI, may be at increased risk for CTE development.

CTE is described as a progressive neurodegenerative disorder affecting individuals exposed to head injury that results in cognitive, behavioral, and/or motor deficits. Existing clinical data are limited, observational in nature, and subject to methodological concerns, thus preventing the establishment of a broad clinical and scientific consensus on the existence of, and diagnostic criteria for, CTE. ${ }^{5-10}$

The present article reviews the potential causes of CTE with a focus on head injury (frequency, type, exposure) followed by a summary of what is known of the limited epidemiological data. A summary of clinical manifestations is presented followed by a section on animal models that attempts to model the neuropathology of head injury. To help facilitate earlier diagnosis of CTE, neuroimaging and biospecimen biomarkers are reviewed. The literature review ends with a discussion of the research needed to draw definitive conclusions between exposure to head injury, CTEassociated pathology, and clinical symptoms.

\section{Methodology}

This literature review searched PubMed, the Defense Technical Information Center (DTIC), Google, and Google Scholar using the search terms in Table 1 . These search terms were generated in collaboration with the United States (US) Department of Defense (DoD) Blast Injury Research Program Coordinating Office and the 2015 International State-of-the-Science meeting planning committee. The inclusion criteria were: English language articles only, clinical and animal model studies, documents available for public distribution (Distribution A) from DTIC, and articles published in the last 10 years (between 2005 and 2015, inclusive). Older publications were included when potentially critical to understanding the topic.

Articles meeting the inclusion criteria were reviewed to determine if they merited inclusion in the literature review based on whether they directly informed the following research questions:

- What is the current evidence describing the pathophysiological basis of CTE?

a. What biological processes following head injury are associated with the development of CTE?

b. What advances in neuroimaging or biomarkers of CTE may lead to the development of diagnostic tools or therapeutic strategies?

- What associations are known between the mechanism(s) of head injury (e.g., single or multiple exposures, impact or nonimpact injury) and the development of CTE?

a. Does the frequency of exposure to head injury correlate with the development of CTE?

b. Are there any known distinctions between how impact injury, nonimpact injury, and blast-induced injury are associated with the development of CTE?

Articles were reviewed for the following elements:

- Study design

- Study population (e.g., military, athletes)

- Outcome measures (e.g., histology, cognitive/behavioral symptoms)

- Results and statistics (when available)

- Conclusions, study limitations, and recommendations relevant to research questions 
TABle 1. Search Terms

\begin{tabular}{|c|c|c|c|c|}
\hline Condition & & Pathology & Outcome measure(s) & $\begin{array}{c}\text { Study } \\
\text { population(s) }\end{array}$ \\
\hline Alzheimer disease & Motor neuron disease & Activated kinases & Assessment & Animal models \\
\hline Auditory & Neurodegeneration & $\begin{array}{l}\text { Apolipoprotein E (ApoE) } \\
\text { genotype }\end{array}$ & Computational models & Athletes \\
\hline Behavioral disorder & Neurodegenerative & Astrocytes & Diagnostic & Boxing \\
\hline Blast event & Parkinsonism & Astroglial tangles & $\begin{array}{l}\text { Diffraction spectrum } \\
\text { imaging or DSI }\end{array}$ & Breacher \\
\hline Blast exposure & $\begin{array}{l}\text { Post-concussion syndrome } \\
\text { or PCS }\end{array}$ & Axonopathy & $\begin{array}{l}\text { Diffusion tensor imaging } \\
\text { or DTI }\end{array}$ & Football \\
\hline $\begin{array}{l}\text { Chronic traumatic brain } \\
\text { injury or TBI }\end{array}$ & $\begin{array}{l}\text { Post-traumatic stress disorder } \\
\text { or PTSD }\end{array}$ & Beta-amyloid & $\begin{array}{l}\text { Magnetic resonance } \\
\text { imaging or MRI }\end{array}$ & $\begin{array}{l}\text { International } \\
\text { Space Program }\end{array}$ \\
\hline $\begin{array}{l}\text { Chronic traumatic } \\
\text { encephalopathy } \\
\text { or CTE }\end{array}$ & $\begin{array}{l}\text { Potentially concussive event } \\
\text { or PCE }\end{array}$ & Biomarker & Screening & Military \\
\hline Cognition & Proteinopathies & Epigenetics & $\begin{array}{l}\text { Positron emission } \\
\text { tomography or PET }\end{array}$ & NASA \\
\hline Cognitive deficits & Repetitive head injury & Glymphatics & Treatment & NCAA \\
\hline Concussion & Suicide & Microglia & Near infrared spectroscopy & NFL \\
\hline Headache/migraine & Tauopathy & Neuroendocrine & Doppler ultrasound & $\begin{array}{l}\text { Occupational } \\
\text { blast }\end{array}$ \\
\hline Head trauma & Traumatic brain injury & Neurofibrillary tangles & & Post-mortem \\
\hline Hearing & Traumatic encephalopathy & Neuropathology & & Sports \\
\hline Inflammation & Vascular injury & Neurosensory & & Soccer \\
\hline Late effects of TBI & Vertigo or dizziness & TDP-43 & & Veteran \\
\hline $\begin{array}{l}\text { Mild traumatic brain } \\
\text { injury or mTBI }\end{array}$ & $\begin{array}{l}\text { Eye, retina, optic nerve, } \\
\text { retinal ganglion cells, } \\
\text { photoreceptors }\end{array}$ & & & \\
\hline
\end{tabular}

NASA, National Aeronautics and Space Administration; NCAA, National Collegiate Athletic Association; NFL, National Football League.

Following this strategy, the literature search yielded 359 articles that met the parameters of the search terms and inclusion/exclusion criteria. This literature review includes a total of 191 articles.

\section{Neuropathology}

Broad consensus on the existence of and diagnostic criteria for CTE has not been firmly established in the clinical and scientific community. ${ }^{6-10}$ Multiple academic groups and government organizations, however, are gathering and analyzing evidence to gain insight into the potential links between exposure to head injury and the development of CTE. ${ }^{1-16}$ A recent National Institutes of Health (NIH) consensus workshop began to establish the pathognomonic (i.e., uniquely indicative) features of CTE required for diagnosis. $^{17}$

Defining the pathology of CTE is an active area of research and collaboration. To date, all clinical neuropathological evidence describing CTE has been gathered from post-mortem autopsy of individuals with a history of exposure to head injury ${ }^{18}$ and include macroscopic (i.e., gross anatomical) and microscopic (i.e., cellular and molecular) pathological abnormalities. Although CTE shares a number of characteristics with other neurodegenerative diseases, including Alzheimer disease (AD), Parkinson disease (PD), and frontotemporal lobar degeneration (FTLD), it is thought to have unique pathological features. ${ }^{12,13,17}$

\section{Macroscopic neuropathology}

Multiple investigators had described previously gross anatomical abnormalities found during autopsy of brains with pathology consistent with the current understanding of CTE. ${ }^{13,19}$ These ab- normalities (Fig. 1), which may result from underlying neurodegenerative processes, include an overall reduction in brain weight, ${ }^{20}$ the enlargement of ventricles, ${ }^{21}$ atrophy of functional brain structures, ${ }^{22}$ cavum septum pellucidum, ${ }^{23}$ and depigmentation of the locus coeruleus and substantia nigra. ${ }^{20}$ Other observations describe relatively more modest gross anatomical findings, ${ }^{10}$ including a lack of cerebral atrophy and milder depigmentation of the substantia nigra and locus coeruleus. ${ }^{14,24}$ Recent consensus work determined that "Macroscopic abnormalities in the septum pellucidum (cavum, fenestration), disproportionate dilatation of the 3rd ventricle or signs of previous brain injury" were supportive criteria for diagnosis of CTE. ${ }^{17}$

\section{Microscopic neuropathology}

The microscopic pathological abnormalities associated with CTE seen during post-mortem examination include several histological observations thought to reflect intracellular and intercellular processes of neurodegeneration.

Tau protein aggregation. The unique pattern of hyperphosphorylated tau (p-tau) protein accumulation in neurofibrillary tangles (NFTs) and/or astrocytic tangles (ATs) is considered to be a primary neuropathological sign of CTE. ${ }^{25}$ The NIH consensus workshop determined that perivascular accumulation of p-tau proteins in neurons, astrocytes, and cell processes in an irregular pattern at the depths of cortical sulci was pathognomonic of CTE (Fig. 1). ${ }^{17}$ Autopsy examinations across multiple studies describe abnormal tau aggregates in several brain areas, including superficial layers of the cerebral cortex, subcortical nuclei, and brainstem. ${ }^{12-14,26}$ Differences 
NORMAL

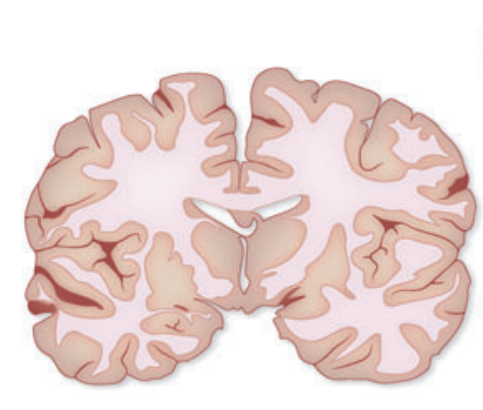

CTE NEUROPATHOLOGY

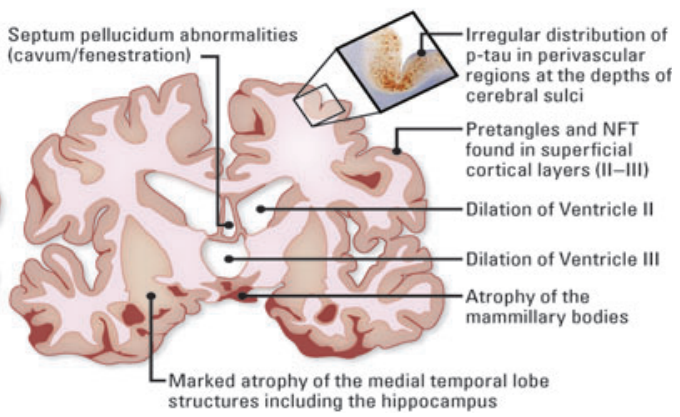

FIG. 1. Neuropathology of chronic traumatic encephalopathy (CTE). Coronal sections of normal brain (left) and brain with CTE neuropathology (right). Macroscopic neuropathology includes dilation of ventricles (II and III), abnormalities of septum pellucidum, atrophy of the mammillary bodies and medial temporal lobe structures. Microscopic neuropathology includes the irregular distribution of p-tau in perivascular regions at the depths of cerebral sulci* and in pre-tangles and neurofibrillary tangles (NFTs) found in superficial cortical layers (II-III). *CTE neuropathology identified by National Institute of Neurological Disorders and Stroke consensus working group as required for diagnosis. Content reproduced from Acta Neuropathol. 2016;131:75-86. (C2016, with permission from SpringerOpen.

in the literature remain, however, regarding the volume and location of these tau protein aggregates. ${ }^{10,27}$

Tauopathies are a class of neurodegenerative diseases characterized by the aggregation of p-tau protein ${ }^{28}$ that are thought to be associated with head injury. ${ }^{29}$ Other tauopathies include AD, progressive supranuclear palsy, ${ }^{30,31}$ Pick disease, ${ }^{32}$ and Huntington disease. ${ }^{33}$ Recent efforts to establish a neuropathological distinction between $\mathrm{AD}$ and CTE suggests that the latter is distinguished by the widespread presence of NFTs in perivascular areas, particularly at the depths of sulci, and in superficial cortical laminae and astrocytes. ${ }^{12,17,34}$ The normal function of tau protein is to stabilize microtubules; however, aberrant p-tau causes the formation of protein aggregates and NFTs, which may contribute to the development of CTE. ${ }^{35}$ It is unknown how head injury leads to tau pathology, but it is thought that hyperphosphorylation of tau may be an early step in the development of CTE. ${ }^{28}$

TAR DNA-binding protein 43 aggregation. Transactive response DNA-binding protein (TDP-43) functions as a transcriptional regulator in the central nervous system ${ }^{36}$ and the presence of TDP-43 aggregates is another pathological feature observed in the post-mortem examination of brains with pathology consistent with the current understanding of CTE.25 This pathological feature is not unique to CTE, because aberrant TDP-43 aggregates are also observed in other neurodegenerative diseases, ${ }^{37,38}$ including motor neuron disease (MND), ${ }^{39}$ amyotrophic lateral sclerosis, and FTLD. ${ }^{40}$ Distribution of TDP-43 aggregates has been reported in the brainstem; basal ganglia; diencephalon; medial temporal lobe; frontal, temporal, and insular cortices; and subcortical white matter. ${ }^{39}$

Beta-amyloid plaque formation. The presence of betaamyloid $(\mathrm{A} \beta)$ plaques has been reported at various levels and distributions in brains with pathology consistent with the current understanding of CTE. ${ }^{13,14,41,42}$ Whether $\mathrm{A} \beta$ neuropathology can be used to identify CTE has been called into question given that these peptide plaques are also associated with $\mathrm{AD} .{ }^{26} \mathrm{~A}$ recent study, however, suggests that $\mathrm{A} \beta$ deposition is associated with a pathological and clinical progression of CTE and in an accelerated trajectory compared with normal aging. ${ }^{42}$

Axonal injury. Axonal injury has been described in brains with pathology consistent with the current understanding of CTE.
Multifocal axonal varicosities have been observed in the frontal and temporal cortex and in subcortical white matter tracts in the brains of CTE cases. ${ }^{12,14,41}$ The extent and severity of axonal injury has been observed to increase with the severity of other pathological features of CTE. ${ }^{12}$ Intercellular events after axonal injury, including microglial and astrocyte activation, are thought to be potential mechanistic links between TBI and CTE. ${ }^{35,43}$

Neuroinflammation. Neuroinflammation has been reported in cases with pathology consistent with the current understanding of CTE. ${ }^{13,44}$ There is evidence that persistent neuroinflammation is associated with microglial and astroglial activation, potentially playing a role in long-term neurodegeneration. ${ }^{45}$ It is unclear, however, whether neuroinflammation, which is known to persist for years after TBI in humans, has a causative relationship with neurodegenerative processes potentially associated with CTE. ${ }^{46}$

Vascular pathology. Vascular degeneration and impaired cerebral hemodynamic regulation may also be related to CTE. McKee and associates ${ }^{12}$ noted small amounts of vascular amyloid in brains with pathology consistent with the current understanding of CTE. ${ }^{12}$ In addition, McKee and Robinson ${ }^{47}$ describe microvasculopathies including acute intrapontine hemorrhage in posterior cerebral artery territories, widespread hypoxic-ischemic injury, acute intraventricular hemorrhage, and hemosiderin-containing macrophages within vascular walls of the thalamus in a case series of four US military veterans with blast exposure and history of at least one concussion. Similarly, in a study of brain samples from athletes who died within six months of concussion $(n=117)$, McKee and colleagues ${ }^{44}$ noted perivascular microgliosis and astrocytosis across many cases, as well as dot-and spindle-shaped neurites proximal to small blood vessels at the depth of the sulci in four cases, and tau pathology in neurons and neurites surrounding a microbleed site in one case. Cerebral microvascular pathology was also present in a mouse model of CTE resulting from a single blast exposure-notably, the presence of hydropic perivascular astrocytic end-feet associated with abnormal capillaries. ${ }^{48}$

Vascular pathologies were reported in brain samples of individuals exposed to repeated head injury going back to a 1989 case series of professional boxers. ${ }^{49}$ The authors highlight hemosiderin contained in macrophages or free proximal to cerebral blood vessels, in the meninges, the subpial region, and/or around the cranial 
nerves in approximately 39\% of boxers for whom death was not related to an acute boxing injury. They caution, however, that the degree of hemorrhage observed in these cases was minor and expressed hesitation in linking these pathologies individually to the complex neurological manifestations of CTE (referred to as dementia pugilistica in the publication). Nonetheless, a more recent study has linked exposure to repeated head injury with impaired cerebral hemodynamic function. ${ }^{50}$ As assessed through transcranial Doppler ultrasound, near-infrared spectroscopy, and mean arterial pressure measurement, professional boxers demonstrated impairments in dynamic cerebral autoregulation and cerebrovascular reactivity to changes in $\mathrm{CO}_{2}$ compared with matched controls.

\section{Classifications of CTE}

Two research groups have proposed classification frameworks for CTE based on neuropathological observations. Omalu and coworkers ${ }^{14}$ proposed four CTE phenotypes thought of as parallel pathologies. ${ }^{14}$ McKee and colleaues ${ }^{12}$ proposed four CTE stages that describe progressive neuropathological changes. These frameworks reflect an emerging understanding of the neuropathology of CTE, not rigid or absolute classifications. ${ }^{10}$ Criteria for both frameworks is informed by the presence of $\mathrm{A} \beta$ plaques and related neuritic plaques despite the recent understanding that these features may not be associated with CTE. ${ }^{26}$

In the CTE phenotypic classification framework proposed by Omalu and coworkers ${ }^{14}$ (Table 2), phenotype I is described as sparse to frequent NFTs and neuritic threads (NTs) in the cerebral cortex and brainstem. Phenotype II also includes NFTs and NTs in the basal ganglia and cerebellum in addition to diffuse amyloid plaques. Phenotype III is defined by a combination of moderate to frequent NFTs and NTs predominately in the brainstem with absent to sparse NFTs and NTs in the cerebral cortex and basal ganglia and none in the cerebellum. Phenotype IV is defined by a combination of absent to sparse NFTs and NTs in the cerebral cortex, brainstem, and basal ganglia, an absence of NFTs and NTs in the cerebellum,

Table 2. Phenotypic Classification of Diverse Chronic Traumatic Encephalopathy Pathologies ${ }^{14}$

Phenotype Characteristics

I - Sparse to frequent NFT and NT in the cerebral cortex and brainstem but without involvement of basal ganglia and cerebellum

- No diffuse amyloid plaques in the cerebral cortex

II

- Sparse to frequent NFTs and NTs in the cerebral cortex and brainstem and may include pathology in the basal ganglia and cerebellum

- Presence of diffuse amyloid plaques in the cerebral cortex

III - Brainstem predominant: moderate to frequent NFTs and NTs in the brainstem nuclei, absent or sparse NFTs and NTs in the cerebral cortex, basal ganglia, and cerebellum

- No diffuse amyloid plaques in the cerebral cortex

IV

- Incipient: absent or sparse NFTs and NTs in the cerebral cortex, brainstem, and basal ganglia

- No cerebellar involvement

- No diffuse amyloid plaques in the cerebral cortex

NFT, neurofibrillary tangles; NT, neuritic threads. and an absence of diffuse amyloid plaques in the cerebral cortex. Across all four phenotypes, there is a possibility of observing varying degrees of NFTs and NTs in the hippocampus with or without diffuse amyloid plaques.

According to the classification framework of progressive pathological stages proposed by McKee and associates ${ }^{12}$ (Table 3), CTE begins focally, usually perivascularly, at the depth of the sulci in the frontal cerebral cortex, as well as in the superficial layers of the cerebral cortex. Over time, the pathology develops to involve widespread regions of the medial cortex, medial temporal lobe, diencephalon, basal ganglia, brainstem, and spinal cord. Stages I and II are considered mild forms of CTE and are characterized by NFTs in focal epicenters of the frontal cortices. Stages III and IV represent severe forms of CTE, with more widespread tau involvement. Validation of the proposed stages, including their clinicopathological correlation, has not been completed.

\section{Neuropathological diagnosis}

Currently, there are no pre-mortem diagnostic criteria for CTE. Recent proposals for post-mortem CTE diagnostic criteria ${ }^{12}$ have been followed by an NIH consensus workshop, ${ }^{17}$ which established required neuropathological diagnostic criteria for CTE, supportive criteria for a diagnosis of CTE, and exclusions to a primary diagnosis of CTE (Table 4).

\section{Exposure to Head Injury}

The existing clinical literature is not sufficient to determine whether CTE is associated with head injury frequency (e.g., single vs. multiple exposures) or head injury type (e.g., impact, nonimpact, blast). Data about the frequency or type of head injury exposure are not collected systematically or consistently across, or sometimes within, CTE case series or case studies. Most CTE studies characterize head injury exposure as exposure to sport or occupation (e.g., football, boxing) without including data describing head injury frequency, severity, or the elapsed time between multiple injuries. Head injury exposure in these cases is assumed, but not necessarily confirmed or quantified, making comparisons between studies difficult. Among the studies that do include data about the occurrence of head injuries in CTE cases, including frequency, type, and/or severity, this information is gathered retrospectively from family interviews and/or medical records, which are subjective and carry other potential biases. In addition, a high rate of duplication (i.e., re-reporting cases across multiple publications) exists in the clinical CTE literature. ${ }^{51}$

\section{Head injury exposure data in CTE cases}

A recent review of 153 unique individuals with pathology consistent with the current understanding of CTE characterized exposure to head injury by categorizing cases according to sports participation, veteran status, or miscellaneous exposure types. ${ }^{51}$ Within each category, additional information about head injury incidence (e.g., motor vehicle accidents, IEDs) was included when available, but was not available consistently across cases. The authors note that although all cases had a "history of head trauma," documentation of severity, frequency, and concussion was "highly variable" in the literature.

McKee and Robinson ${ }^{47}$ presented post-mortem case reports for four military veterans with pathological signs of CTE, three of which were reported previously. ${ }^{48}$ Exposure to head injury across the four cases is described as exposure to blast (from "single" to "several"), 
Table 3. Progressive Classification of Chronic Traumatic Encephalopathy ${ }^{12}$

\begin{tabular}{|c|c|c|}
\hline Stage & Macroscopic pathology & Microscopic pathology \\
\hline I & $\begin{array}{l}\text { - Normal brain weight } \\
\text { - Brain pathology is unremarkable }\end{array}$ & $\begin{array}{l}\text { - Focal epicenters of perivascular p-tau and neurofibrillary } \\
\text { and astrocytic tangles involving the sulcal depths and } \\
\text { typically affecting the superior and dorsolateral frontal } \\
\text { cortices } \\
\text { - Approximately half of Stage I p-tau pathology also shows } \\
\text { rare TDP-43 neurites } \\
\text { - No presence of A } \beta \text { plaques, except in subjects over } 50 \\
\text { years of age }\end{array}$ \\
\hline II & $\begin{array}{l}\text { - Normal brain weight } \\
\text { - Subtle brain pathology exhibited mild enlargement of the } \\
\text { frontal horns of the lateral and third ventricles, cavum } \\
\text { septum pellucidum, and pallor of the locus coeruleus and } \\
\text { substantia nigra }\end{array}$ & $\begin{array}{l}\text { - Multiple epicenters of perivascular foci of p-tau NFT and } \\
\text { neurites at the depths of the sulci with localized spread } \\
\text { from epicenters to the superficial layers of the adjacent } \\
\text { cortex } \\
\text { - Mild TDP-43 pathology as abnormal neurites and } \\
\text { neuronal inclusions } \\
\text { - No neurofibrillary p-tau involvement in the medial } \\
\text { temporal lobe } \\
\text { - A } \beta \text { plaques found in } 19 \% \text { of subjects if over } 50 \text { years } \\
\text { of age }\end{array}$ \\
\hline III & $\begin{array}{l}\text { - Mild reduction in brain weight } \\
\text { - Mild cerebral atrophy with dilatation of the lateral and } \\
\text { third ventricles } \\
\text { - Septal abnormalities } \\
\text { - Moderate depigmentation of the locus coeruleus and mild } \\
\text { depigmentation of the substantia nigra atrophy of the } \\
\text { mammillary bodies and thalamus }\end{array}$ & $\begin{array}{l}\text { - Widespread p-tau pathology in the frontal, insular, } \\
\text { temporal, and parietal cortices } \\
\text { - Neurofibrillary pathology in the amygdala, hippocampus, } \\
\text { and entorhinal cortex } \\
\text { - A } \beta \text { plaques found in } 13 \% \text { of cases }\end{array}$ \\
\hline IV & $\begin{array}{l}\text { - Marked reduction in brain weight } \\
\text { - Atrophy of the cerebral cortex } \\
\text { - Marked atrophy of the medial temporal lobe, thalamus, } \\
\text { hypothalamus, and mammillary bodies } \\
\text { - Diffuse atrophy of the white matter and thinning of the } \\
\text { corpus callosum, particularly the isthmus } \\
\text { - Severe thinning of the hypothalamic floor }\end{array}$ & $\begin{array}{l}\text { - Severe p-tau pathology affecting most regions of the } \\
\text { cerebral cortex and the medial temporal lobe, sparing } \\
\text { the calcarine cortex } \\
\text { - Severe p-tau pathology in the diencephalon, basal ganglia, } \\
\text { brainstem, and spinal cord } \\
\text { - Astrocytosis of the white matter } \\
\text { - Neuronal loss in the cerebral cortex } \\
\text { - Marked axonal loss of subcortical white matter tracts } \\
\text { - Widespread TDP-43 deposits } \\
\text { - Marked loss of myelinated nerve fibers }\end{array}$ \\
\hline
\end{tabular}

TDP-43, Transactive response DNA-binding protein; A $\beta$, amyloid beta; NFT, neurofibrillary tangles.

as well as concussion symptoms and/or history. ${ }^{47}$ The authors also reviewed a single case study of a veteran exposed to "multiple mortar blasts and IEDs" whose autopsy showed neuropathological changes consistent with CTE. ${ }^{52}$ In addition, McKee and Robinson ${ }^{47}$ reviewed 23 post-mortem cases of veterans with pathology consistent with the current understanding of CTE. In this cohort, obtained from the Boston VA Brain Bank, exposure to head injury is characterized by sports participation in 16 subjects, exposure to IED blast or military concussion in five subjects (three of whom also played high school football), and other exposures, such as assault, motor vehicle accident, and post-traumatic epilepsy. Frequency and severity of head injury in these cases was not reported. ${ }^{47}$

In a case series of retired football players from the Canadian Football League, three of six players studied had pathology consistent with the current understanding of CTE at autopsy. ${ }^{6}$ These three CTE cases were reported to have sustained multiple concussions; however, the authors note that actual frequency or severity information could not be determined. Although clinical details of these cases were gathered retrospectively from family interviews, treating physicians, and medical records, the source of the concussion history was not specified by the authors.

The case series review by McKee and associates ${ }^{12}$ included 35 American football players with pathology consistent with the cur- rent understanding of CTE for whom head injury exposure information was available from structured retrospective interviews of family members. Statistical analyses found that the number of concussions reported by family members was not correlated with the pathological stage of CTE (concussion frequency data was not provided by authors). The number of years played, the number of years since retirement, and the age at death was correlated with CTE stage in these cases, however. The authors also did not report the collection of head injury exposure information for 17 football players included in the case series review who did not exhibit pathology consistent with the current understanding of CTE. This case series also included 21 military veterans, 16 of whom were athletes (eight professional football players) and nine of whom experienced combat. The authors note that three veterans sustained TBI and four were exposed to IEDs or explosive munitions.

Characterization of head injury exposure for 11 persons with pathology consistent with the current understanding of CTE by Omalu and colleagues ${ }^{14}$ is limited to that of contact sports participation. Although retrospective clinical symptom information was collected through next-of-kin interviews, the correlation of symptoms and pathology was not reported.

McKee and coworkers ${ }^{41}$ presented case reports of one football player and two boxers with pathology consistent with the current 
Table 4. Preliminary National Institute of Neurological Disorders and Stroke diagnostic Criteria for Chronic Traumatic Eencephalopathy ${ }^{17}$

\section{Required for diagnosis of CTE}

The pathognomonic lesion consists of p-tau aggregates in neurons, astrocytes, and cell processes around small vessels in an irregular pattern at the depths of the cortical sulci

\section{Supportive neuropathological features of CTE}

a. p-Tau-related pathologies:

1. Abnormal p-tau immunoreactive pretangles and NFTs preferentially affecting superficial layers (layers II-III), in contrast to layers III and $\mathrm{V}$ as in $\mathrm{AD}$

2. In the hippocampus, pretangles, NFTs or extracellular tangles preferentially affecting CA2 and pretangles and prominent proximal dendritic swellings in CA4. These regional p-tau pathologies differ from the preferential involvement of CA1 and subiculum found in $\mathrm{AD}$

3. Abnormal p-tau immunoreactive neuronal and astrocytic aggregates in subcortical nuclei, including the mammillary bodies and other hypothalamic nuclei, amygdala, nucleus accumbens, thalamus, midbrain tegmentum, and isodendritic core (nucleus basalis of Meynert, raphe nuclei, substantia nigra and locus coeruleus)

4. p-Tau immunoreactive thorny astrocytes at the glial limitans most commonly found in the subpial and periventricular regions

5. p-Tau immunoreactive large grain-like and dot-like structures (in addition to some threadlike neurites)

b. Non-p-tau-related pathologies:

1. Macroscopic features: disproportionate dilatation of the third ventricle, septal abnormalities, mammillary body atrophy, and contusions or other signs of previous traumatic injury

2. TDP-43 immunoreactive neuronal cytoplasmic inclusions and dot-like structures in the hippocampus, anteromedial temporal cortex and amygdala

III. Age-related p-tau astrogliopathy that may be present; non-diagnostic and non-supportive

1. Patches of thorn-shaped astrocytes in subcortical white matter

2. Subependymal, periventricular, and perivascular thorn-shaped astrocytes in the mediobasal regions

3. Thorn-shaped astrocytes in amygdala or hippocampus

Reprinted from Acta Neuropathol. 2016;131:75-86, (c) 2016, with permission from SpringerOpen

CTE, chronic traumatic encephalopathy; NFT, neurofibrillary tangles; AD, Alzheimer disease.

understanding of CTE. Retrospectively collected head injury exposure information is documented for the football player (at least 11 concussions during college and the professional career, only one medically confirmed) and one of the boxers (a mild injury during the teenage years). The authors also review 47 cases previously documented in the literature, including boxing, football, and other sport activities. A review of these cases reveals that the characterization of exposure to head injury was limited to that of exposure to sport, with the exception of a soccer player who suffered a single severe head injury and a circus dwarf who was knocked unconscious approximately a dozen times.

\section{Frequency of head injury exposure}

Case reports of individuals with pathology consistent with the current understanding of CTE have not investigated how the frequency of head injury exposure affects the development of CTE by, for example, comparing subjects with single versus multiple head injury exposures. Some investigators have explored associations between injury frequency and other neurological outcomes that are thought to be related to CTE; however, very few conclusions can be drawn given mixed evidence and methodological concerns. A metaanalysis comparing the effect of exposure to multiple versus single mild TBI (mTBI) in athletes finds minimal, nonsignificant differences in cognitive function and symptom complaints between the two exposure frequencies, although secondary analysis finds poorer performance in delayed memory and executive measures in the multiple mTBI exposure group. ${ }^{53}$ Previously, investigators have reported an association between the number of concussions sustained and cognitive impairments, as well as self-reported clinical depression in retired professional football players. ${ }^{54,55}$ Methodological limitations attributed to errors inherent in self-reporting, however, have put these findings subsequently in question. ${ }^{10,56}$

\section{Type of head injury exposure}

Existing case reports are not always conducive for determining how head injury type impacts the development of CTE. For example, in football players with pathology consistent with the current understanding of CTE, some have a history of at least one concussion and some do not. ${ }^{26}$ This raises the possibility that subconcussive injury, or nonsports-related injury (in this population), is associated with the induction of CTE. In a study of brain samples from the general population, however, tau pathology consistent with CTE was found in 21 of 66 individuals with exposure to contact sports, but no tau pathology was seen in individuals with documented head trauma not related to sport (e.g., falls, car accidents, assault). ${ }^{34}$ In addition, some football players with a documented history of multiple concussions do not exhibit pathology consistent with the current understanding of CTE on post-mortem examination. ${ }^{6}$ These findings highlight the complexities of linking particular injury etiologies with CTE.

\section{Epidemiology}

The incidence of CTE-associated pathology and/or symptoms in at-risk populations has not yet been determined, prompting a call for population-based studies. ${ }^{27,57}$ Early estimates of CTE prevalence in boxers $(17 \%)^{58}$ are likely inapplicable to modern realities given changes over the past several decades, including the nature of boxing, diagnostic criteria, the inclusion of other at-risk populations in the field (e.g., football), and an evolving understanding of CTE. ${ }^{18,57,59}$ In an autopsy study of 321 professional football players, Gavett and associates ${ }^{60}$ estimated prevalence of CTE at $3.7 \%$. Strikingly, another study with brain samples from the general population observed tau pathology consistent with the current understanding of CTE in $32 \%$ of males with exposure to contact sports. ${ }^{34}$ It is important to note that the samples used in that study 
were from a brain bank of neurodegenerative disorders; however, samples from individuals with previous neuropathological diagnosis of a primary tauopathy were excluded. Studies investigating the risk of neurodegenerative disorders secondary to repetitive head injury exposure yield mixed results, ${ }^{61}$ because some investigators have observed greater rates of neurodegenerative symptoms in contact sport athletes, ${ }^{54,62}$ but others find no increased rates in similar populations. ${ }^{63}$ Because the International Classification of Diseases does not list CTE as a cause of death, it is also possible that individuals with CTE have been classified incorrectly as having other neurodegenerative diseases. ${ }^{62}$

Despite inconclusive epidemiological evidence, the primary risk factor for CTE appears to be exposure to head impacts from concussive or subconcussive events. This determination is largely the result of observations that most persons with pathology consistent with the current understanding of CTE have a history of repetitive brain trauma. ${ }^{64}$ Other factors related to or influencing injury exposure may play a role as well, including the length of boxing or professional football career. ${ }^{57}$

Studies of genetic CTE risk factors have focused primarily on the apolipoprotein E (ApoE) genotyping, particularly the $\varepsilon 4$ allele, which is a known risk factor for $\mathrm{AD},{ }^{65}$ but when taken together, existing studies yield inconclusive evidence. The ApoE $\varepsilon 4$ variations have been observed in case studies of individuals with pathology consistent with the current understanding of CTE, ${ }^{14}$ and some evidence suggests neuropathological impairment in contact sport athletes with the ApoE $\varepsilon 4$ variation. ${ }^{66,67}$ More recent studies, however, have noted that abnormal ApoE allelic variation in CTE cases does not appear to be greater than that of the general population. ${ }^{12,51}$

\section{Clinical Manifestations}

Clinical symptoms of CTE are generally thought to occur years after the initial exposure to trauma. Clinical symptoms associated with CTE include chronic psychiatric illnesses (e.g., depression), headache, cognitive problems, and motor impairment. ${ }^{12,14,27,51,57}$ The CTE-associated clinical symptoms are often variable and nonspecific, and overlap with symptoms of multiple neurodegenerative diseases, including AD, PD, FTLD, MND, as well as post-concussive syndrome. ${ }^{27,51,57}$ Experts have noted an extensive overlap of clinical symptoms associated with CTE and post-traumatic stress disorder in military populations. ${ }^{47,52}$ Although suicidality is commonly reported, links between CTE and suicide have been questioned in the literature and are not well established. ${ }^{5,51,68}$

Defining clear links between clinical changes and CTE neuropathology continues to be a research focus. McKee and colleagues ${ }^{12}$ correlate clinical findings with a proposed framework of progressive neuropathological staging for CTE. In addition, Stern and colleagues ${ }^{69}$ propose two types of clinical presentation variants, one termed "behavior/mood" and one termed "cognitive.",69 Stein and coworkers ${ }^{42}$ reported subsequently that the cognitive variant might be associated with $\mathrm{A} \beta$ deposition. While the broad range of symptoms associated with CTE has been questioned as clinically meaningless, ${ }^{9}$ investigators have suggested recently diagnostic criteria for CTE, ${ }^{70,71}$ including the proposal of traumatic encephalopathy syndrome. ${ }^{72,73}$

To address existing questions about links between CTE neuropathology and clinical/behavioral changes, established diagnostic criteria for longitudinal studies are needed. ${ }^{74}$ In addition, methodological gaps, common in the existing body of case reports, must be addressed. Data reporting is inconsistent across case studies, and a high rate $(43 \%)$ of duplication (i.e., re-reporting cases across multiple publications) has been described. ${ }^{51}$ Conclusions derived from case studies, which are often referred to researchers by families with concerns about neurobehavioral problems, ${ }^{74}$ are limited by the significant likelihood of selection (ascertainment) biases. ${ }^{51,75}$ In addition, pre-mortem symptom data, which are often derived from interviews with family members, is not objective and is subject to recall biases. ${ }^{76}$

\section{Animal Models}

Animal models may offer insights into neuropathological and neurobehavioral abnormalities thought to be associated with CTE. To date, few investigators have developed animal models designed to reflect CTE specifically, ${ }^{48,77}$ but certain animal models of TBI may be useful because they replicate injury exposure conditions associated with CTE, such as blunt force or blast-induced TBI. Caution must be applied, however, in interpreting these results because there are no animal models currently that accurately and precisely demonstrate the neuropathological features of CTE. This has been identified as an opportunity for research and development. ${ }^{78}$

A recent comprehensive review of animal models used in mTBI research is provided by Schultz and associates. ${ }^{79}$ Studies of blunt force TBI are conducted primarily using weight drop, controlled cortical impact (CCI), or fluid percussion injury (FPI) mechanisms in rodents, all of which are tunable to achieve a range of TBI severities. In the weight drop model, a weight is dropped through a guide tube onto a steel plate attached to a rodent's exposed skull. This technique produces diffuse injury after single and repeat drops, but some model variability is introduced through the potential for rebounding weight impact. In the CCI model, a narrow impactor is pneumatically or electromagnetically driven to strike an animal's exposed dura, creating a focal brain injury. Schultz and associates ${ }^{79}$ highlight that although groups have reduced the velocity and/or impact depth to induce mTBI, some studies report injuries consistent with more moderate-severe TBI. In recent years, researchers have begun investigating CCI as a closed-head injury model in nonanesthetized animals, which may be a higher fidelity model. Finally, the FPI model creates both focal and diffuse injury via a pressure pulse delivered to the exposed dura through a fluidcontaining tube. The FPI can be used to induce single or multiple mild impact injuries.

Existing animal models of blast-induced TBI include the shocktube and open-field model. The shock-tube model induces injury by delivering blast waves from a gas-driven pneumatic tube system to the head of an anesthetized animal. Some investigators secure the neck, head, torso, and abdomen of the animal to minimize movement and tertiary blast effects. ${ }^{80}$ Others use a Kevlar vest to protect the thorax of the anesthetized animal from the blast shockwave and avoid transvascular transmission of a hydrodynamic pulse. ${ }^{81}$ The open-field model typically involves placing anesthetized animals in compartments on a platform in close proximity (e.g., 4-7 m) to an ordinance (e.g., trinitrotoluene) and then exposing the animal to blast waves from a controlled explosion. ${ }^{82}$ Recently, application of a lithotripsy machine has been developed to generate shockwaves that induce brain injuries in mice. ${ }^{83}$

Comparison of results across studies of blast-induced TBI is challenging because small differences in shock tube or ordinance design and animal placement can significantly affect the characteristics of the impacting blast wave, which are difficult to measure. ${ }^{79}$ Investigators have emphasized that precise replication TBI etiology is of secondary importance to generating clinically relevant and repeatable results, however. ${ }^{78}$ 


\section{Neuropathological analysis}

Animal models of blunt force-induced and blast-induced TBI described above have revealed few histological abnormalities matching observations in humans with pathology consistent with the current understanding of CTE.

Tau. Tau aggregation in animal models after TBI varies across different studies. In several rodent studies, tau concentrations increase after a single impact $\mathrm{TBI}^{48,84-86}$ or blast-related $\mathrm{TBI}^{48}$ In contrast, other studies have failed to demonstrate a difference in tau aggregation when comparing single-impact TBI and shaminjury groups. ${ }^{87-89}$

Animal model studies investigating the impact of repeated TBI on tau aggregation also vary. In some studies, animals exposed to repeated TBI did not have elevated brain levels of p-tau $24 \mathrm{~h}$, 34 days, 10 weeks, 4 months, 6 months, and 12 months post-injury (as measured by immunohistochemistry, enzyme-linked immunosorbent assay, and Western blot). ${ }^{89-91}$ Other studies, however, reported that repeated TBI increases tau levels in the brain postinjury. ${ }^{85,92-95}$ Of the studies that found increased tau postinjury, one reported region-specific increases (cortex, amygdala, and hippocampus) of tau immunoreactivity up to six months after repeated $\mathrm{TBI}^{77}$

One reason rodent models do not reflect accurately the neuropathology of CTE cases may be that the endogenous rodent tau aggregates differently than the human tau protein. Mouse models expressing human tau isoforms have been created in an attempt to generate a more precise rodent model of head injury. The hTau mouse expresses all six human tau isoforms, ${ }^{96}$ and the T44 mouse expresses the shortest human tau isoform. ${ }^{97}$ In hTau mice, Ojo and colleagues ${ }^{98}$ demonstrated increased expression of phosphorylated tau 21 days after repetitive injury; however, tau expression in these animals did not increase after a single head injury. ${ }^{98}$

Axonal injury. Axonal injury is a common neuropathological consequence of closed head injury. ${ }^{99,100}$ Because axonal injury and subsequent intercellular events, including activation of microglia and astrocytes, are thought to be potential mechanistic links between TBI and CTE ${ }^{35,43}$ animal models may provide a means to study these associations.

Traditionally, axonal injury was thought to be limited to acute periods after head injury; however, recent evidence has identified axonal degeneration in human brains many years after the initial injury. ${ }^{99,101}$ Evidence of chronic axonal injury indicates a potential pathology contributing to chronic symptoms of CTE. In closed head injury animal models, the presence of persistent axon damage with corresponding activation of astrocytes and microglial cells has been described in mice that underwent single and repetitive mTBI exposure. ${ }^{85,89,102-104}$ Activation of astrocytes and microglial cells suggestive of CTE pathology also appears to be a common feature of blast injuries in rodents. ${ }^{48,105,106}$

\section{Neurobehavioral analysis}

Animal model studies have also described neurobehavioral abnormalities reflecting clinical manifestations thought to be associated with CTE. Two common neurobehavioral tests used with rodent models are the Morris water maze test for cognitive assessment (i.e., spatial learning and memory) ${ }^{107}$ and the accelerating rotarod test for motor assessment (i.e., balance and sensorimotor coordination). ${ }^{108}$ Multiple investigators have demonstrated cognitive ${ }^{109-111}$ and motor ${ }^{109,112}$ deficits after exposures to impact- related TBI. Neurobehavioral deficits have also been observed after blast-related TBI exposure in rodents. ${ }^{48,81,113,114}$

In addition, animal model studies have explored the impact of TBI exposure frequency on neurobehavioral abnormalities. Numerous investigators have demonstrated that multiple TBI impact-related exposures result in more pervasive and long-lasting neurobehavioral deficits when compared with single-exposure injuries. ${ }^{89,109-112}$ Studies also suggest greater cognitive impairments when the interval between multiple impacts to the head is shorter. ${ }^{88,115}$

\section{Biomarkers}

The successful development of objective in vivo biomarkers could enable the identification of CTE pathology in living persons, which would greatly enhance our understanding of the underlying biological mechanisms and could inform potential diagnostic, treatment, and prevention strategies. Investigators are pursuing neuroimaging modalities and biospecimen analytes as potential predictive biomarkers of CTE.

\section{Neuroimaging}

Current neuroimaging research relevant to CTE biomarkers generally focuses on two approaches. One approach is the detection of molecules associated with CTE pathology (e.g., tau, A $\beta$ ). The second approach is detecting structural or molecular changes associated with head injury, which is thought to contribute to the development of CTE. It is important to note that there are no longitudinal studies correlating in vivo neuroimaging data directly with post-mortem CTE-associated pathology, and the techniques described here currently only describe differences in populations with brain injury or disease and controls. Successful development of noninvasive diagnostic approaches for CTE are critically reliant on first defining the disease as a distinct entity with appropriate neuropathological and clinical validation.

Positron emission tomography. Positron emission tomography (PET) can detect the presence and distribution of specific molecules using trace amounts of radioactive ligands that bind to molecules of interest. Investigators are developing PET radioligands to image pathology associated with CTE, ${ }^{116}$ including aggregations of tau ${ }^{117}$ and $\mathrm{A} \beta{ }^{118}$ PET is also being used to assess changes in metabolic activity in the brain associated with exposure to head trauma.

Several PET radioligands targeting tau have shown potential as CTE biomarkers, and some are being investigated in clinical trials. Maruyama and coworkers ${ }^{119}$ demonstrated that the $\left[{ }^{11} \mathrm{C}\right] \mathrm{PBB} 3$ radioligand exhibits specificity for tau in transgenic mouse models and human subjects with probable AD. A Phase II clinical trial is under way to determine whether $\left[{ }^{11} \mathrm{C}\right] \mathrm{PBB} 3$ can detect tau aggregates in patients with a history of head injury (single and multiple exposures included). ${ }^{120}$

In addition, two related radioligands, $\left[{ }^{18} \mathrm{~F}\right] \mathrm{T} 807$ and $\left[{ }^{18} \mathrm{~F}\right] \mathrm{T} 808$, have high affinity and selectivity for p-tau in humans. ${ }^{121,122} \mathrm{Mul}$ tiple clinical trials are under way to investigate the use of $\left[{ }^{18} \mathrm{~F}\right] \mathrm{T} 807$ as a potential biomarker of CTE. ${ }^{123,124}$

PET imaging of tau faces several challenges. ${ }^{125}$ Tau protein aggregates are expressed intracellularly, which requires the corresponding imaging ligand to cross the blood-brain barrier and cell membrane. Tau aggregates are also subject to several post-translational modifications that alter the ultrastructural conformation of the aggregates and diminish radioligand binding. Tau ligands have an affinity for $\mathrm{A} \beta$ aggregates as well, which poses a 
challenge for characterization of CTE pathology because both protein aggregates may be present in different anatomical locations and $\mathrm{A} \beta$ pathology is significant in $\mathrm{AD}$. Nevertheless, at least six new classes of tau radioligands have been developed, each with different levels of affinity and specificity to tau relative to $\mathrm{A} \beta .^{126}$

PET imaging of $\mathrm{A} \beta$ aggregates has been demonstrated using a $\left[{ }^{18}\right.$ F]FDDNP radioligand; ${ }^{118}$ however, unlike [18F]T807, binding is relatively nonselective and also labels NFTs (i.e., tau). ${ }^{127}$ In football players with a history of concussion (single or multiple), $\left[{ }^{18}\right.$ F]FDDNP PET demonstrates increased signaling in the amygdala and subcortical brain regions, which is potentially indicative of CTE ${ }^{128}$ Barrio and colleagues ${ }^{129}$ describe differences in $\left[{ }^{18} \mathrm{~F}\right]$ FDDNP signal patterns between football players with $\mathrm{mTBI}$ and veterans with blast-induced mTBI. ${ }^{129}$ These observations suggest that the radioligand may be useful in identifying and characterizing CTE. The $\left[{ }^{18} \mathrm{~F}\right]$ FDDNP radioligand also binds with extracellular $\mathrm{A} \beta$ plaques and intracellular NTFs in patients with $\mathrm{AD}^{127,130}$ and Down syndrome, ${ }^{131}$ so discrimination between tauopathies must rely on regional signal differences.

PET imaging with $\left[{ }^{18} \mathrm{~F}\right] \mathrm{FDG}$ PET can measure glucose metabolic activity, which reflects the functional states of brain structures. ${ }^{116}\left[{ }^{18} \mathrm{~F}\right]$ FDG PET imaging has found hypometabolism (relative to controls) in the frontal lobe anterior to the Broca area, the posterior cingulate cortex, the posterior parietal lobe, and the cerebellum of boxers. ${ }^{132}$ The authors note that the presence of hypometabolism in the frontal lobe anterior to the Broca area is not observed generally after TBI from other etiologies and suggest that it may be caused by impacts to the side of the head. The hypometabolism of the posterior cingulate cortex and the posterior parietal lobes, however, is similar to that seen in patients with $\mathrm{AD},{ }^{133}$ which may be responsible for the AD-like cognitive decline seen in boxers. ${ }^{132}$ Hypometabolism in the cerebellum, however, is not seen generally in AD patients until very advanced stages, ${ }^{134}$ suggesting it may complement other methods as a way to differentiate between $\mathrm{AD}$ and TBI as the cause of cognitive impairments. Together, these results suggest that $\left[{ }^{18} \mathrm{~F}\right] \mathrm{FDG}$ PET could be used potentially as a biomarker for TBI-related neurodegenerative processes resulting from exposure to head injury.

Researchers have also pursued the use of PET to characterize TBI-related neuroinflammation through use of radioligands selective for activated microglia. Elevated uptake of $\left[{ }^{11} \mathrm{C}\right] \mathrm{R}-\mathrm{PK} 11195$, which binds to a transmembrane protein expressed in activated microglia, was observed in the brains of patients with moderate to severe TBI from several months to years post-injury. ${ }^{135,136}$ Increased binding of $\left[{ }^{11} \mathrm{C}\right]-\mathrm{DPA}-713$, a second-generation radioligand with greater specificity for activated microglia, was observed in the brain regions associated with TBI of nine former NFL players compared with controls. ${ }^{137}$

Diffusion tensor imaging. Diffusion tensor imaging (DTI) can visualize white matter axon tracts, enabling investigators to detect abnormalities not visible using conventional magnetic resonance imaging or computed tomography imaging methodologies. ${ }^{116}$ DTI revealed significant white matter changes in a highschool contact sport athlete after a single concussion. ${ }^{138}$ Further, significant white matter changes can be detected in contact sport athletes exposed to multiple subconcussive injuries in the absence of clinically evident concussion. ${ }^{138,139}$ DTI findings have also supported a link between axonal abnormalities and executive impairment after TBI. ${ }^{140}$

Studies in athletes with a history of concussion suggest that white matter integrity may be a marker of cognitive and/or mood disorders after brain injury. In a study of retired professional American football players with a history of concussion (single or multiple; $n=26$ ), DTI revealed a significant, negative correlation between the fractional anisotropy of four white matter tracts (forceps minor, right uncinate fasciculus, right frontal aslant tract, and left superior longitudinal fasciculus) and total score on the Beck Depression Inventory, suggesting a correlation between white matter integrity and depression. ${ }^{141}$ Indeed, the mean fractional anisotropy of the forceps minor distinguished depressed from nondepressed participants with a sensitivity of $100 \%$ and specificity of $95.2 \%$ (five participants were classified as depressed by their Beck Depression Inventory scores).

Hart and associates ${ }^{142}$ also investigated white matter integrity in former professional American football players with a history of concussion (single or multiple). In this study, fractional anisotropy was significantly lower across many bilateral frontal and parietal regions, the corpus callosum, and the left temporal lobe of participants with cognition and/or mood impairments than of agematched controls ( $n=14$ per group).

Several DTI studies that have investigated white matter integrity in veterans with exposure to blast- and/or impact-related injuries report different findings. Some studies detect abnormalities in multiple, diffuse areas, ${ }^{143-146}$ while Mac Donald and colleagues ${ }^{147}$ report abnormalities restricted to the cerebellum. Detection of spatially heterogeneous areas of decreased fractional anisotropy may indicate a potential DTI-based biomarker for blast-related mTBI. ${ }^{148}$ In contrast, one recent DTI study found no significant differences in white matter integrity between veterans exposed to blast-related injury and controls. ${ }^{149}$

Magnetic resonance spectroscopy. Magnetic resonance spectroscopy (MRS) is a noninvasive method of measuring brain chemistry in vivo that can be applied to detect changes in brain metabolites after TBI. ${ }^{16,150}$ MRS has been used to detect common brain metabolites altered by brain injury including decreased $\mathrm{N}$ acetyl aspartate (NAA; indicating neuronal damage), increased choline (Ch) and lipid (indicating membrane damage and diffuse axonal injury), increased combined glutamate and glutamine (Glx; indicating excitotoxic effects of the brain), and increased myoinositol (indicating brain injury from membrane damage and/or as a result of astrocytosis). ${ }^{150}$

Single voxel MRS has demonstrated a significant decrease in Glx and NAA in the primary motor cortex and NAA in the prefrontal cortex in concussed athletes as compared with nonconcussed athletes. ${ }^{151}$ Using single voxel MRS techniques, increased levels of $\mathrm{Ch}$ and Glx were found in retired professional athletes with CTE symptoms, when compared with age-matched, healthy controls. ${ }^{152}$ Use of advanced spectroscopy methods, specifically two-dimensional localized correlated spectroscopy, illustrated changes in Glx and Ch typically captured with conventional MRS, but also recorded increases in phenylalanine and fucose from the brains of former athletes, which cannot be measured by conventional MRS. ${ }^{150,153}$ Although imaging changes in these brain metabolites using MRS may help describe pathological changes after single or repetitive brain injury, it can be difficult to distinguish between natural changes with aging and those of injury. ${ }^{154}$

Researchers have been using MRS to study the effects of blast injury in veterans. Reductions of NAA relative to brain metabolites Ch and creatine $(\mathrm{Cr}), \mathrm{NAA} / \mathrm{Ch}$ and NAA/Cr ratios, respectively, are thought to indicate brain injury. ${ }^{155}$ Significant hippocampal reductions of NAA/Ch and NAA/Cr have been observed in veterans when compared with controls. ${ }^{156,157}$ 
Functional magnetic resonance imaging. Functional magnetic resonance imaging (fMRI) can investigate structural and functional changes of the brain after brain injury. ${ }^{158-160} \mathrm{Re}$ searchers have used fMRI to evaluate functional disruptions in both concussive and subconcussive injury groups, even in the absence of overt clinical symptoms. ${ }^{161}$ Given its ability to detect deficits in subconcussive injury, fMRI may hold promise for future investigations of CTE-related changes. ${ }^{150}$

\section{Biospecimens}

Effective biospecimen-based biomarkers would provide a more accessible, cost-effective, and deployable method for identifying CTE in vivo than neuroimaging modalities that are resource intensive and located in fixed brick-and-mortar facilities. There are few studies focused on biospecimen-based CTE biomarkers, in part because of the pathological and symptological similarities to established neurodegenerative diseases. ${ }^{116}$ Investigators, however, have been pursuing the measurement of proteins and/or microRNAs found in cerebrospinal fluid (CSF) or blood plasma as potential biomarkers of TBI, which may support the identification of CTE pathology in vivo. ${ }^{162,163}$

CSF. Although CSF is considered a potential source of TBI biomarkers given its direct contact with the brain and nervous system, ${ }^{116}$ the lumbar puncture required to sample CSF poses obvious disadvantages. Research on CSF biomarkers of TBI has focused on axonal proteins, such as neurofilament light and tau. ${ }^{164} \mathrm{~A}$ longitudinal study of amateur boxers demonstrated increased levels of neurofilament light and tau in CSF after bouts. ${ }^{165}$ The increases of neurofilament light suggested dose dependency (increases were more pronounced in boxers who sustained several head punches), but the utility of this marker is called into question given that protein levels returned to normal after three months without bouts.

Additional studies in amateur boxers have described increases in CSF proteins, in particular neurofilament light, tau, and glial fibrillary acidic protein (GFAP), that correlated with exposure to head trauma. ${ }^{166-168}$ The number of days in which the proteins remained elevated varied, indicating that they may be best used as markers of acute injury. Additional studies are needed to validate blast biomarkers and determine the most effective time to take CSF samples after exposure.

Blood plasma. Although blood-based biomarker sampling poses lower risk than the lumbar punctures that CSF approaches require, plasma biomarkers have their drawbacks, including: (1) dilution of the brain-specific protein by the large volume of plasma and in the extracellular fluid of peripheral organs, (2) degradation of the biomarker candidate by blood proteases, (3) clearance of the protein by hepatic metabolism or renal excretion, and (4) analyses of brain proteins in blood that can be confounded by release of the same protein from peripheral tissues. ${ }^{164}$

Recent research has identified several potential blood plasmabased biomarkers of TBI. Serum levels of S100 calcium-binding protein beta $(\mathrm{S}-100 \beta)$ were increased in patients with severe TBI and demonstrate a strong correlation to clinical outcome. ${ }^{169,170}$ In addition, the ratio of GFAP to ubiquitin carboxy-terminal hydrolase-L1 in plasma may be characteristic of a focal or diffuse $\mathrm{TBI}^{171}$ and may change after multiple concussive or subconcussive head injuries. This ratio may offer insight into the development of CTE. ${ }^{116}$ Transient, severity-dependent, and time-dependent elevations of tau levels in serum were detected after TBI in rats. ${ }^{84}$ In addition, Olivera and colleagues ${ }^{172}$ reported elevated concentrations of plasma tau protein in military personnel with TBI from both blast and nonblast cohorts. ${ }^{172}$

Another plasma-based TBI biomarker of potential relevance to CTE is neuron-specific enolase. ${ }^{173}$ Elevated levels of this protein were detected in boxers after they abstained from boxing for two months when compared with healthy controls. The $\mathrm{S}-100 \beta$, brainderived neurotrophic factor, and heart-type fatty acid binding protein did not change, however. These results suggest that neuronspecific enolase may remain elevated for an extended period postinjury and could be a useful biomarker for making a diagnosis in athletes and patients who have had multiple concussive and subconcussive head injuries.

\section{Chronic Progressive Neurodegeneration after Moderate or Severe TBI}

A potential confounder to the study of CTE resulting from multiple subconcussive or mild concussive impacts is the observation of single moderate to severe TBI events also leading to chronic progressive neurodegeneration. Imaging and pathology studies suggest volumetric and structural changes accompanied by inflammation and axonal degradation can persist years after the initial injury.

In an MRI study conducted five and 20 months after injury, more than $96 \%$ of participants who sustained a mild to severe TBI (at least $70 \%$ had severe TBI) demonstrated progressive atrophy in at least one region of the brain compared with normative controls, with $75 \%$ showing atrophy in at least three regions (regions studied: left and right hippocampus, corpus callosum, and ventricle to brain volume ratio). ${ }^{174}$ Similarly, other studies have shown that persons with moderate or severe TBI have progressive decreases in hippocampal volume up to 2.5 years after injury ${ }^{175}$ and experienced greater atrophy than controls in the brainstem, parahippocampal gyrus, thalamus, inferior longitudinal fasciculus, superior longitudinal fasciculus, internal capsule, external capsule, forceps minor, superior and anterior corona radiata, and the splenium, body, and genu of the corpus callosum four years after injury. ${ }^{176}$

As assessed by DTI, individuals with moderate or severe TBI had greater declines in fractional anisotropy of numerous white matter tracts and greater increases in white and gray matter mean diffusivity than controls at 12 months compared with two months after injury. ${ }^{177}$ These results are corroborated in a separate DTI study demonstrating progressive white matter degeneration in the corpus callosum over a four-year period. ${ }^{178}$ In a study of brain samples from persons who sustained a single moderate or severe TBI, inflammation, axonal pathology differing from that observed in acute stages of injury, and white matter degradation were observed in the corpus callosum up to 18 years after injury. ${ }^{101}$ Notably, NFTs were present in higher densities and wider distributions in brain samples of approximately one-third of individuals who sustained a single moderate or severe TBI than in matched controls for at least one year after injury. ${ }^{179}$ In that study, NFTs in TBI samples were identified primarily in superficial cortical layers, clustering at the depths of the sulci.

Although studies of changes in cognitive performance in the years after a TBI event are varied, one group reported a significant decline $2-5$ years after injury on at least two neuropsychological measures in $27.3 \%$ of participants who sustained moderate or severe TBI. ${ }^{180}$ As the fields of research in CTE and chronic progressive neurodegeneration after moderate or severe TBI progress, it will be critical to consider the uniqueness and commonalities of 
the anatomical and cognitive effects of each injury etiology in setting diagnostic criteria and potential treatment regimens.

\section{CTE and Blast Exposure}

Given that the first case of pathology was consistent with the current understanding of CTE observed after blast exposure was reported in $2011,{ }^{52}$ the understanding of potential links between blast and development of CTE is still nascent. ${ }^{159}$ Goldstein and associates $^{48}$ reported a case series of three veterans with a history of blast exposure- two with a history of concussion and one with exposure to multiple blasts but no previous blunt-force concussion. The authors note perivascular tau-positive NFTs located at the depths of the sulci and axonal degradation and distortion in subcortical white matter, which were consistent with pathological findings in the same study from amateur American football players with histories of multiple concussive and/or subconcussive injuries, and are consistent with the current understanding of the pathological presentation of CTE. McKee and Robinson ${ }^{47}$ describe an additional case of a veteran exposed to multiple blast events, noting pathology of severe axonal loss and a single focus of perivascular NFTs at the sulcal depth of the inferior parietal cortex. It was not reported whether this individual had a history of blunt-force concussion.

Although these case reports suggest that a relationship between blast exposure and development of pathology consistent with the current understanding of CTE cannot be ruled out, this assertion is complicated by an additional study that did not observe tau pathology in five veterans exposed to blast, three with the confound of opiate abuse. ${ }^{181}$ The subjects in that study, however, were only stated to have exposure to a single blast event, only one had a history of a blunt-force concussive injury, and widespread diffuse axonal injury was observed in these individuals that differed from the axonal injury pattern seen after car accidents or opiate overdose.

A few groups have begun to investigate whether exposure to blast can be linked to CTE through pre-clinical models. In a rat model of repeated side-impact blast exposure using a shock tube, there was significantly more hyperphosphorylated tau, located perivascularly and in the contralateral hemisphere, in blast animals than in controls. ${ }^{182}$ This study also demonstrated significantly more NFT precursors (i.e., CP-13) in the contralateral hippocampus of blast animals, again with perivascular localization, than in controls. Cognitive deficits in blast animals relative to controls were also observed.

Two additional groups have investigated CTE-like pathology after single blast exposure in mice. Goldstein and associates ${ }^{48}$ detected NFT precursors (CP-13) in the superficial layers of the cerebral cortex and bilateral phosphorylated tauopathy using a shock tube with the animal placed inside the tube. ${ }^{48}$ Huber and coworkers ${ }^{183}$ also placed animals within a shock tube, facing the blast wave head on, and reported phosphorylated tau species, including CP-13, in the cortex, hippocampus, and cerebellum of blast animals. Both studies are careful not to suggest that their results imply a single blast exposure can lead to CTE in humans, but all studies provide pre-clinical evidence that blast exposure can lead to the initial stages of NFT formation. These efforts set the stage for further pre-clinical investigation of whether and how blast exposure can lead to pathology consistent with the current understanding of CTE.

\section{Treatment and Prevention Strategies}

Because there are no treatments for CTE, current mitigation strategies focus on prevention of head injury and/or concussion. ${ }^{61,164}$ Protective headgear can prevent severe injuries such as penetrating injuries, skull fracture, and intracranial hemorrhage, but they do not appear to mitigate the incidence or severity of sports-related concussion $^{184,185}$; some have suggested that the use of helmets in sports enables or promotes aggressive play and increases the risk for head injury. ${ }^{186}$ Other prevention strategies in sports include rule changes and return-to-play guidelines. ${ }^{185}$ The DoD has developed return-toactivity guidelines for service members after mTBI. ${ }^{187}$

Although consensus on the understanding of CTE is still being established and diagnostic criteria are still under development, researchers are investigating potential treatment approaches. One approach has been to target tau pathology as a potential intervention strategy. Kondo and colleagues ${ }^{188}$ blocked tauopathy progression in mice with the application of an antibody that interrupted an early stage of tau development, (cistauosis) after TBI. ${ }^{188}$ Recent work describing the impact of acetylation on tau aggregation suggests a potential therapeutic target for CTE. ${ }^{189,190}$ In addition, pharmacological inhibition of a metabolic enzyme, monoacylglycerol lipase, in a mouse model of repetitive closed-head injury reduced several neuropathological signs of CTE, including tau phosphorylation and TDP-43 protein aggregation. ${ }^{95}$ Because of the neuropathological similarities with $\mathrm{AD}$ and $\mathrm{TBI}$, potential pharmacological and behavioral interventions for these conditions could also be applied to CTE. ${ }^{74,191}$

\section{Discussion}

CTE represents a major public health issue, given the number of athletes and service members who are exposed to concussive and/or subconcussive events. The current state of the science has generated an initial consensus on the neuropathology of CTE. ${ }^{17}$ The evidence, however, does not allow for a conclusive determination of whether exposure to head injury is sufficient and causal in the development of CTE pathology. Existing clinical data are limited, observational in nature, and subject to methodological concerns. These realities have led some to question whether existing data are adequate to treat CTE as a unique neurodegenerative disease. . $^{7,27}$

Existing neuropathological evidence describes brain abnormalities after exposure to head injury, which may be associated with CTE development and may reflect underlying biological processes. Recent consensus establishing perivascular p-tau aggregation in cortical sulci depths as unique indications of CTE represents the most conclusive pathological evidence to date. ${ }^{17}$ Pathophysiological mechanisms explaining how tau aggregation causes or contributes to clinical symptoms of tauopathies, including $\mathrm{AD}$, have yet to be determined, and it has not definitively been determined whether or how tau pathology drives or causes clinical manifestations of CTE. ${ }^{27}$ More broadly, it is still not clear what other macroscopic and microscopic (e.g., A $\beta$, TDP-43) pathological findings are unique to CTE, given that autopsy reports are inconsistent ${ }^{7}$ and that these same pathologies are also associated with aging ${ }^{8}$ and multiple neurodegenerative diseases. ${ }^{7}$

The identification of biomarkers for the in vivo detection of CTE pathology would advance ongoing research needs. Investigators are working to develop neuroimaging and biospecimen-based biomarkers, targeting the pathophysiological mechanisms associated with CTE (e.g., tau aggregates) and the biological processes after head injury exposure. Pre-mortem identification of CTE could benefit prevention and treatment. Current pre-clinical and clinical development of therapeutic or rehabilitative strategies is also targeting pathophysiological mechanisms associated with CTE and the biological processes after head injury exposure.

Existing clinical evidence is not sufficient to determine whether variations in head injury frequency (e.g., single versus multiple 
exposures) or head injury type (e.g., impact, nonimpact, blast) are differentially associated with CTE. Data about frequency or type of head injury exposure are not collected systematically or consistently across, or sometimes even within, CTE case series or case studies. Most CTE studies characterize head injury exposure simply as exposure to sport or occupation (e.g., football, boxing) without including data describing head injury frequency, severity, or the time elapsed between injuries.

Other fundamental questions exist about the links between exposure to head injury, CTE-associated pathology, and clinical symptoms. For example, evidence does not conclusively support that retired athletes exhibit a unique neurodegenerative pathology or have higher rates of associated clinical symptoms relative to the general population. ${ }^{9}$ Alternative hypotheses have been described recently by Iverson and colleagues, ${ }^{27}$ such as the possibility that neurotrauma reduces a cerebral reserve normally protecting persons from development of neurodegenerative disorders, or that tau pathology is silent clinically such that symptoms are because of other, potentially multi-factorial, causes. ${ }^{27}$

Given these challenges, it is too early to draw conclusions regarding links between blast exposure and the development of CTE, although recent case studies and pre-clinical work provide evidence for a relationship between blast exposure and pathology consistent with the current understanding of CTE. With hundreds of thousands of active duty service members and veterans having been exposed to blast events, often more than once, it is essential for the DoD and scientific community to continue and expand research in this field.

\section{Research needs}

Limitations to the conclusions that can be drawn about links between exposure to head injury, CTE-associated pathology, and clinical symptoms stem in part from the characteristics of existing evidence and methodological issues. For example, post-mortem CTE autopsy cases, which are often referred to researchers by families with concerns about neurobehavioral problems, ${ }^{74}$ are limited by significant selection (ascertainment) biases. ${ }^{7,51,75}$ Data about the clinical symptoms associated with CTE are retrospective and often derived from interviews with family members, which make the data subjective and limited by recall biases. ${ }^{76}$

CTE has drawn significant public and media attention given the large at-risk population (e.g., military personnel, contact sport athletes). Experts have noted concern over the potential clinical and legal consequences of a widespread misunderstanding of CTE. ${ }^{10}$ Given these factors, the need for additional research is clear, and investigators have called for specific actions: ${ }^{9,27,72}$

- Initiation of cross-sectional, prospective, longitudinal, and/or epidemiological studies; initial work could compare retired athletes and service members or veterans with a history of blast exposure to demographically matched controls and assess whether a higher risk for clinical symptoms is supported; additional work could investigate links between CTE-associated pathology and observed clinical symptoms

- Development of standardized protocols for studying pathology, including establishing control data

- Development of validated clinical diagnostic criteria and clinical research criteria

- Continued biomarker development, such as determining whether PET imaging can detect differences in tau between groups with and without head injury exposure, with different clinical manifestations, including comorbidities (as well as control subjects)

\section{Acknowledgments}

The present literature review was performed under contract number W81XWH-08-D-0025 in support of the 2015 International State-of-the-Science Meeting entitled, "Does Repeated Blastrelated Trauma Contribute to the Development of Chronic Traumatic Encephalopathy (CTE)?" The meeting was held November 3-5, 2015, in McLean, Virginia.

This review informed a 2015 International State-of-the-Science meeting and includes sources published 2005-October 2015.

\section{Author Disclosure Statement}

No competing financial interests exist.

The views expressed in this article are those of the authors and do not reflect the official policy of the US Government, the Department of Defense, or the Departments of the Army, Navy, or Air Force. The use of trade names in this publication does not imply endorsement by the authors or the United States Government, the Department of Defense, or the Departments of the Army, Navy, or Air Force, nor does it imply criticism of similar products or devices not mentioned.

\section{References}

1. Martland HS. (1928). Punch drunk. JAMA 91, 1103-1107.

2. Critchley, M. (1957). Medical aspects of boxing, particularly from a neurological standpoint. Br. Med. J. 1, 357-362.

3. Omalu, B., DeKosky, S.T., Minster, R.L., Kamboh, M.I., Hamilton, R.L., and Wecht, C.H. (2005). Chronic traumatic encephalopathy in a National Football League player. Neurosurgery 57, 128-134.

4. DVBIC. (2012). DoD worldwide numbers for TBI. Available at: dvbic.dcoe.mil/dod-worldwide-numbers-tbi. Accessed September 1, 2017.

5. Iverson, G.L. (2014). Chronic traumatic encephalopathy and risk of suicide in former athletes. Br. J. Sports Med. 48, 162-164.

6. Hazrati, L.N., Tartaglia, M.C., Diamandis, P., Davis, K., Green, R.E., Wennberg, R., Wong, J.C., Ezerins, L., and Tator, C.H. (2013). Absence of chronic traumatic encephalopathy in retired football players with multiple concussions and neurological symptomatology. Front. Hum. Neurosci. 7, 222.

7. Karantzoulis, S., and Randolph, C. (2013). Modern chronic traumatic encephalopathy in retired athletes: what is the evidence? Neuropsychol. Rev. 23, 350-360.

8. McCrory, P., Meeuwisse, W.H., Kutcher, J.S., Jordan, B.D., and Gardner, A. (2013). What is the evidence for chronic concussionrelated changes in retired athletes: behavioural, pathological and clinical outcomes? Br. J. Sports Med. 47, 327-330.

9. Randolph, C. (2014). Is chronic traumatic encephalopathy a real disease? Curr. Sports Med. Rep. 13, 33-37.

10. Wortzel, H.S., Brenner, L.A., and Arciniegas, D.B. (2013). Traumatic brain injury and chronic traumatic encephalopathy: a forensic neuropsychiatric perspective. Behav. Sci. Law. 31, 721-738.

11. Hinds, S. (2014). Chronic traumatic encephalopathy. Defense and Veterans Brain Injury Center.

12. McKee, A.C., Stern, R.A., Nowinski, C.J., Stein, T.D., Alvarez, V.E., Daneshvar, D.H., Lee, H.S., Wojtowicz, S.M., Hall, G., Baugh, C.M., Riley, D.O., Kubilus, C.A., Cormier, K.A., Jacobs, M.A., Martin, B.R., Abraham, C.R., Ikezu, T., Reichard, R.R., Wolozin, B.L., Budson, A.E., Goldstein, L.E., Kowall, N.W., and Cantu, R.C. (2013). The spectrum of disease in chronic traumatic encephalopathy. Brain 136, 43-64.

13. McKee, A.C., Stein, T.D., Kiernan, P.T., and Alvarez, V.E. (2015). The neuropathology of chronic traumatic encephalopathy. Brain Pathol. $25,350-364$

14. Omalu, B., Bailes, J., Hamilton, R.L., Kamboh, M.I., Hammers, J., Case, M., and Fitzsimmons, R. (2011). Emerging histomorphologic phenotypes of chronic traumatic encephalopathy in American athletes. Neurosurgery 69, 173-183.

15. Riley, D.O., Robbins, C.A., Cantu, R.C., and Stern, R.A. (2015). Chronic traumatic encephalopathy: contributions from the Boston University Center for the Study of Traumatic Encephalopathy. Brain Inj. 29, 154-163. 
16. Saigal, R. and Berger, M.S. (2014). The long-term effects of repetitive mild head injuries in sports. Neurosurgery 75, Suppl 4, S149-S155.

17. McKee, A.C., Cairns, N.J., Dickson, D.W., Folkerth, R.D., Keene, C.D., Litvan, I., Perl, D.P., Stein, T.D., Vonsattel, J.P., Stewart, W., Tripodis, Y., Crary, J.F., Bieniek, K.F., Dams-O'Connor, K., Alvarez, V.E., Gordon, W.A., and TBI/CTE group. (2016). The first NINDS/NIBIB consensus meeting to define neuropathological criteria for the diagnosis of chronic traumatic encephalopathy. Acta Neuropathol. 131, 75-86.

18. Gardner, A., Iverson, G.L., and McCrory, P. (2014). Chronic traumatic encephalopathy in sport: a systematic review. Br. J. Sports Med. 48, 84-90.

19. Stern, R.A., Riley, D.O., Daneshvar, D.H., Nowinski, C.J., Cantu, R.C., and McKee, A.C. (2011). Long-term consequences of repetitive brain trauma: chronic traumatic encephalopathy. PM R 3, Suppl 2, S460-S467.

20. Corsellis, J.N., Bruton, C.J., and Freeman-Browne, D. (1973). The aftermath of boxing. Psychol. Med. 3, 270-303.

21. Williams, D.J., and Tannenberg, A.E. (1996). Dementia pugilistica in an alcoholic achondroplastic dwarf. Pathology 28, 102-104.

22. Roberts, G.W., Whitwell, H.L., Acland, P.R., and Bruton, C.J. (1990). Dementia in a punch-drunk wife. Lancet 335, 918-919.

23. Hof, P.R., Bouras, C., Buée, L., Delacourte, A., Perl, D.P., and Morrison, J.H. (1992). Differential distribution of neurofibrillary tangles in the cerebral cortex of dementia pugilistica and Alzheimer's disease cases. Acta Neuropathol. 85, 23-30.

24. Omalu, B., Bailes, J., Hammers, J.L., and Fitzsimmons, R.P. (2010). Chronic traumatic encephalopathy, suicides and parasuicides in professional American athletes: the role of the forensic pathologist. Am. J. Forensic Med. Pathol. 31, 130-132.

25. Kiernan, P.T., Montenigro, P.H., Solomon, T.M., and McKee, A.C. (2015). Chronic traumatic encephalopathy: a neurodegenerative consequence of repetitive traumatic brain injury. Semin. Neurol. 35, $20-28$.

26. Stein, T.D., Alvarez, V.E., and McKee, A.C. (2014). Chronic traumatic encephalopathy: a spectrum of neuropathological changes following repetitive brain trauma in athletes and military personnel. Alzheimers. Res. Ther. 6, 4.

27. Iverson, G.L., Gardner, A.J., McCrory, P., Zafonte, R., and Castellani, R.J. (2015). A critical review of chronic traumatic encephalopathy. Neurosci. Biobehav. Rev. 56, 276-293.

28. Takashima, A. (2013). Tauopathies and tau oligomers. J. Alzheimers Dis. $37,565-568$.

29. Abisambra, J. and Scheff, S. (2014). Brain injury in the context of tauopathies. J. Alzheimers. Dis. 40, 495-518.

30. Hauw, J.J., Daniel, S.E., Dickson, D., Horoupian, D.S., Jellinger, K., Lantos, P.L., McKee, A., Tabaton, M., and Litvan, I. (1994). Preliminary NINDS neuropathologic criteria for Steele-RichardsonOlszewski syndrome (progressive supranuclear palsy). Neurology 44, 2015-2019.

31. Litvan, I., Hauw, J.J., Bartko, J.J., Lantos, P.L., Daniel, S.E., Horoupian, D.S., McKee, A., Dickson, D., Bancher, C., Tabaton, M., Jellinger, K., and Anderson, D.W. (1996). Validity and reliability of the preliminary NINDS neuropathologic criteria for progressive supranuclear palsy and related disorders. J. Neuropathol. Exp. Neurol. 55, 97-105.

32. Rizzini, C., Goedert, M., Hodges, J.R., Smith, M.J., Jakes, R., Hills, R., Xuereb, J.H., Crowther, R.A., and Spillantini, M.G. (2000). Tau gene mutation K257T causes a tauopathy similar to Pick's disease. J. Neuropathol. Exp. Neurol. 59, 990-1001.

33. Fernández-Nogales, M., Cabrera, J.R., Santos-Galindo, M., Hoozemans, J.J., Ferrer, I., Rozemuller, A.J., Hernández, F., Avila, J., and Lucas, J.J. (2014). Huntington's disease is a four-repeat tauopathy with tau nuclear rods. Nat. Med .20, 881-885.

34. Bieniek, K.F., Ross, O.A., Cormier, K.A., Walton, R.L., SotoOrtolaza, A., Johnston, A.E., DeSaro, P., Boylan, K.B., GraffRadford, N.R., Wszolek, Z.K., Rademakers, R., Boeve, B.F., McKee, A.C., and Dickson, D.W. (2015). Chronic traumatic encephalopathy pathology in a neurodegenerative disorders brain bank. Acta Neuropathol, 130, 877-889.

35. Lucke-Wold, B.P., Turner, R.C., Logsdon, A.F., Bailes, J.E., Huber, J.D., and Rosen, C.L. (2014). Linking traumatic brain injury to chronic traumatic encephalopathy: identification of potential mechanisms leading to neurofibrillary tangle development. J. Neurotrauma $31,1129-1138$.
36. Sephton, C.F., Cenik, B., Cenik, B.K., Herz, J., and Yu, G. (2012). TDP-43 in central nervous system development and function: clues to TDP-43-associated neurodegeneration. Biol. Chem. 393, 589-594.

37. Armstrong, R.A., Ellis, W., Hamilton, R.L., Mackenzie, I.R., Hedreen, J., Gearing, M., Montine, T., Vonsattel, J.P., Head, E., Lieberman, A.P., and Cairns, N.J. (2009). Neuropathological heterogeneity in frontotemporal lobar degeneration with TDP-43 proteinopathy: a quantitative study of 94 cases using principal components analysis. J. Neural. Transm. 117, 227-239.

38. Bosque, P.J., Boyer, P.J., and Mishra, P. (2013). A 43-kDa TDP-43 species is present in aggregates associated with frontotemporal lobar degeneration. PLoS ONE 8, e62301.

39. McKee, A.C., Gavett, B.E., Stern, R.A., Nowinski, C.J., Cantu, R.C., Kowall, N.W., Perl, D.P., Hedley-Whyte, E.T., Price, B., Sullivan, C., Morin, P., Lee, H.S., Kubilus, C.A., Daneshvar, D.H., Wulff, M., and Budson, A.E. (2010). TDP-43 proteinopathy and motor neuron disease in chronic traumatic encephalopathy. J. Neuropathol. Exp. Neurol. 69, 918-929.

40. Baloh, R.H. (2011). TDP-43: the relationship between protein aggregation and neurodegeneration in amyotrophic lateral sclerosis and frontotemporal lobar degeneration. FEBS J. 278, 3539-3549.

41. McKee, A.C., Cantu, R.C., Nowinski, C.J., Hedley-Whyte, E.T., Gavett, B.E., Budson, A.E., Santini, V.E., Lee, H.S., Kubilus, C.A., and Stern, R.A. (2009). Chronic traumatic encephalopathy in athletes: progressive tauopathy after repetitive head injury. J. Neuropathol. Exp. Neurol. 68, 709-735.

42. Stein, T.D., Montenigro, P.H., Alvarez, V.E., Xia, W., Crary, J.F., Tripodis, Y., Daneshvar, D.H., Mez, J., Solomon, T., Meng, G., Kubilus, C.A., Cormier, K.A., Meng, S., Babcock, K., Kiernan, P., Murphy, L., Nowinski, C.J., Martin, B., Dixon, D., Stern, R.A., Cantu, R.C., Kowall, N.W., and McKee, A.C. (2015). Beta-amyloid deposition in chronic traumatic encephalopathy. Acta Neuropathol. 130, $21-$ 34.

43. Ling, H., Hardy, J., and Zetterberg, H. (2015). Neurological consequences of traumatic brain injuries in sports. Mol. Cel Neurosc 66, $114-122$.

44. McKee, A.C., Daneshvar, D.H., Alvarez, V.E., and Stein, T.D. (2014). The neuropathology of sport. Acta Neuropathol. 127, 29-51.

45. Faden, A.I., Wu, J., Stoica, B.A., and Loane, D.J. (2015). Progressive inflammation-mediated neurodegeneration after traumatic brain or spinal cord injury. Br. J. Pharmacol. 173, 681-691.

46. Smith, D.H., Johnson, V.E., and Stewart, W. (2013). Chronic neuropathologies of single and repetitive TBI: substrates of dementia? Nat. Rev. Neurol. 9, 211-221.

47. McKee, A.C., and Robinson, M.E. (2014). Military-related traumatic brain injury and neurodegeneration. Alzheimers Dement. 10, Suppl, S242-S253.

48. Goldstein, L.E., Fisher, A.M., Tagge, C.A., Zhang, X.L., Velisek, L., Sullivan, J.A., Upreti, C., Kracht, J.M., Ericsson, M., Wojnarowicz, M.W., Goletiani, C.J., Maglakelidze, G.M., Casey, N., Moncaster, J.A., Minaeva, O., Moir, R.D., Nowinski, C.J., Stern, R.A., Cantu, R.C., Geiling, J., Blusztajn, J.K., Wolozin, B.L., Ikezu, T., Stein, T.D., Budson, A.E., Kowall, N.W., Chargin, D., Sharon, A., Saman, S., Hall, G.F., Moss, W.C., Cleveland, R.O., Tanzi, R.E., Stanton, P.K., and McKee, A.C. (2012). Chronic traumatic encephalopathy in blastexposed military veterans and a blast neurotrauma mouse model. Sci. Transl. Med. 4, 134ra60.

49. Adams, C., and Bruton, C. (1989). The cerebral vasculature in dementia pugilistica. J. Neurol. Neurosurg. Psychiatry 52, 600-604.

50. Bailey, D., Jones, D., Sinnott, A., Brugniaux, J., New, K., Hodson, D., Marley, C., Smirl, J., Ogoh, S., and Ainslie, P. (2013). Impaired cerebral haemodynamic function associated with chronic traumatic brain injury in professional boxers. Clin. Sci. (Lond) 124, 177-189.

51. Maroon, J.C., Winkelman, R., Bost, J., Amos, A., Mathyssek, C., and Miele, V. (2015). Chronic traumatic encephalopathy in contact sports: a systematic review of all reported pathological cases. PLoS One 10, e0117338.

52. Omalu, B., Hammers, J.L., Bailes, J., Hamilton, R.L., Kamboh, M.I., Webster, G., and Fitzsimmons, R.P. (2011). Chronic traumatic encephalopathy in an Iraqi war veteran with posttraumatic stress disorder who committed suicide. Neurosurg. Focus 31, E3.

53. Belanger, H.G., Spiegel, E., and Vanderploeg, R.D. (2010). Neuropsychological performance following a history of multiple selfreported concussions: a meta-analysis. J. Int. Neuropsychol. Soc. 16, 262-267. 
54. Guskiewicz, K.M., Marshall, S.W., Bailes, J., McCrea, M., Cantu, R.C., Randolph, C., and Jordan, B.D. (2005). Association between recurrent concussion and late-life cognitive impairment in retired professional football players. Neurosurgery 57, 719-726.

55. Guskiewicz, K.M., Marshall, S.W., Bailes, J., McCrea, M., Harding, H.P., Matthews, A., Mihalik, J.R., and Cantu, R.C. (2007). Recurrent concussion and risk of depression in retired professional football players. Med. Sci. Sports Exerc. 39, 903-909.

56. Kerr, Z.Y., Marshall, S.W., and Guskiewicz, K.M. (2012). Reliability of concussion history in former professional football players. Med. Sci. Sports Exerc. 44, 377-382.

57. Lenihan, M.W., and Jordan, B.D. (2015). The clinical presentation of chronic traumatic encephalopathy. Curr. Neurol. Neurosci. Rep. 15, 23.

58. Roberts, A.H. (1969). Brain damage in Boxers: A Study of the Prevalence of Traumatic Encephalopathy among Ex-Professional Boxers. Pitman: London.

59. Clausen, H., McCrory, P., and Anderson, V. (2005). The risk of chronic traumatic brain injury in professional boxing: change in exposure variables over the past century. Br. J. Sports Med. 39, 661-664.

60. Gavett, B.E., Stern, R.A., and McKee, A.C. (2011). Chronic traumatic encephalopathy: a potential late effect of sport-related concussive and subconcussive head trauma. Clin. Sports Med. 30 , $179-188$.

61. Jordan, B. (2014). Chronic traumatic encephalopathy and other longterm sequelae. Continuum (Minneap Minn) 20, 1588-1604.

62. Lehman, E.J., Hein, M.J., Baron, S.L., and Gersic, C.M. (2012). Neurodegenerative causes of death among retired National Football League players. Neurology 79, 1970-1974.

63. Savica, R., Parisi, J.E., Wold, L.E., Josephs, K.A., and Ahlskog, J.E. (2012). High school football and risk of neurodegeneration: a community-based study. Mayo Clin. Proc. 87, 335-340.

64. Baugh, C.M., Robbins, C.A., Stern, R.A., and McKee, A.C. (2014). Current understanding of chronic traumatic encephalopathy. Curr. Treat. Options Neurol. 16, 306.

65. Michaelson, D.M. (2014). APOE $\varepsilon 4$ : the most prevalent yet understudied risk factor for Alzheimer's disease. Alzheimers Dement. 10, $861-868$.

66. Jordan, B., Relkin, N., Ravdin, L., Jacobs, A., Bennett, A., and Gandy, S. (1997). Apolipoprotein $\mathrm{e} \in 4$ associated with chronic traumatic brain injury in boxing. JAMA 278, 136-140.

67. Kutner, K.C., Erlanger, D.M., Tsai, J., Jordan, B., and Relkin, N. (2000). Lower cognitive performance of older football players possessing apolipoprotein E \&4. Neurosurgery 47, 651-657.

68. Wortzel, H.S., Shura, R.D., and Brenner, L.A. (2013). Chronic traumatic encephalopathy and suicide: a systematic review. Biomed Res Int 2013, 424280.

69. Stern, R.A., Daneshvar, D.H., Baugh, C.M., Seichepine, D.R., Montenigro, P.H., Riley, D.O., Fritts, N.G., Stamm, J.M., Robbins, C.A., McHale, L., Simkin, I., Stein, T.D., Alvarez, V.E., Goldstein, L.E., Budson, A.E., Kowall, N.W., Nowinski, C.J., Cantu, R.C., and McKee, A.C. (2013). Clinical presentation of chronic traumatic encephalopathy. Neurology 81, 1122-1129.

70. Jordan, B. (2013). The clinical spectrum of sport-related traumatic brain injury. Nat. Rev. Neurol. 9, 222-230.

71. Victoroff, J. (2013). Traumatic encephalopathy: review and provisional research diagnostic criteria. NeuroRehabilitation 32, 211-224.

72. Montenigro, P.H., Baugh, C.M., Daneshvar, D.H., Mez, J., Budson, A.E., Au, R., Katz, D.I., Cantu, R.C., and Stern, R.A. (2014). Clinical subtypes of chronic traumatic encephalopathy: literature review and proposed research diagnostic criteria for traumatic encephalopathy syndrome. Alzheimers. Res. Ther. 6, 68.

73. Montenigro, P.H., Bernick, C., and Cantu, R.C. (2015). Clinical features of repetitive traumatic brain injury and chronic traumatic encephalopathy. Brain Pathol. 25, 304-317.

74. Antonius, D., Mathew, N., Picano, J., Hinds, A., Cogswell, A., Olympia, J., Brooks, T., DiGiacomo, M., Baker, J., Willer, B., and Leddy, J. (2014). Behavioral health symptoms associated with chronic traumatic encephalopathy: a critical review of the literature and recommendations for treatment and research. J. Neuropsychiatry Clin. Neurosci. 26, 313-322.

75. Daneshvar, D.H., Riley, D.O., Nowinski, C.J., McKee, A.C., Stern, R.A., and Cantu, R.C. (2011). Long-term consequences: effects on normal development profile after concussion. Phys. Med. Rehabil. Clin. N. Am. 22, 683-700.
76. McCrory, P., Zazryn, T., and Cameron, P. (2007). The evidence for chronic traumatic encephalopathy in boxing. Sports Med. 37, 467-476.

77. Petraglia, A.L., Plog, B.A., Dayawansa, S., Dashnaw, M.L., Czerniecka, K., Walker, C.T., Chen, M., Hyrien, O., Iliff, J.J., Deane, R., Huang, J.H., and Nedergaard, M. (2014). The pathophysiology underlying repetitive mild traumatic brain injury in a novel mouse model of chronic traumatic encephalopathy. Surg. Neurol. Int. 5, 184.

78. Goldstein, L.E., McKee, A.C., and Stanton, P.K. (2014). Considerations for animal models of blast-related traumatic brain injury and chronic traumatic encephalopathy. Alzheimers Res. Ther. 6, 64.

79. Schultz, S.R., McDonald, S.J., Vonder Haar, C., Meconi, A., Vink, R., van Donkelaar, P., Taneja, C., Iverson, G.L., and Christie, B.R. (2017). The potential for animal models to provide insight into mild traumatic brain injury: translational challenges and strategies. Neurosci. Biobehav. Rev. 76, 396-414.

80. Cernak, I., Merkle, A.C., Koliatsos, V.E., Bilik, J.M., Luong, Q.T., Mahota, T.M., Xu, L., Slack, N., Windle, D., and Ahmed, F.A. (2011). The pathobiology of blast injuries and blast-induced neurotrauma as identified using a new experimental model of injury in mice. Neurobiol. Dis. 41, 538-551.

81. Long, J.B., Bentley, T.L., Wessner, K.A., Cerone, C., Sweeney, S., and Bauman, R.A. (2009). Blast overpressure in rats: recreating a battlefield injury in the laboratory. J. Neurotrauma 26, 827-840.

82. Rubovitch, V., Ten-Bosch, M., Zohar, O., Harrison, C.R., TempelBrami, C., Stein, E., Hoffer, B.J., Balaban, C.D., Schreiber, S., Chiu, W.T., and Pick, C.G. (2011). A mouse model of blast-induced mild traumatic brain injury. Exp. Neurol. 232, 280-289.

83. Divani, A.A., Murphy, A.J., Meints, J., Sadeghi-Bazargani, H., Nordberg, J., Monga, M., Low, W.C., Bhatia, P.M., Beilman, G.J., and SantaCruz, K.S. (2015). A novel preclinical model of moderate primary blast-induced traumatic brain injury. J. Neurotrauma 32, 1109-1116.

84. Liliang, P.C., Liang, C.L., Lu, K., Wang, K.W., Weng, H.C., Hsieh, C.H., Tsai, Y.D., and Chen, H.J. (2010). Relationship between injury severity and serum tau protein levels in traumatic brain injured rats. Resuscitation 81, 1205-1208.

85. Luo, J., Nguyen, A., Villeda, S., Zhang, H., Ding, Z., Lindsey, D., Bieri, G., Castellano, J.M., Beaupre, G.S., and Wyss-Coray, T. (2014). Long-term cognitive impairments and pathological alterations in a mouse model of repetitive mild traumatic brain injury. Front. Neurol. 5, 12.

86. Perez-Polo, J.R., Rea, H.C., Johnson, K.M., Parsley, M.A., Unabia, G.C., Xu, G.Y., Prough, D., DeWitt, D.S., Spratt, H., and Hulsebosch, C.E. (2015). A rodent model of mild traumatic brain blast injury. J. Neurosci. Res. 93, 549-561.

87. Gama Sosa, M.A., De Gasperi, R., Janssen, P.L., Yuk, F.J., Anazodo, P.C., Pricop, P.E., Paulino, A.J., Wicinski, B., Shaughness, M.C., Maudlin-Jeronimo, E., Hall, A.A., Dickstein, D.L., McCarron, R.M., Chavko, M., Hof, P.R., Ahlers, S.T., and Elder, G.A. (2014). Selective vulnerability of the cerebral vasculature to blast injury in a rat model of mild traumatic brain injury. Acta Neuropathol. Commun. 2, 67.

88. Mannix, R., Meehan, W.P., Mandeville, J., Grant, P.E., Gray, T., Berglass, J., Zhang, J., Bryant, J., Rezaie, S., Chung, J.Y., Peters, N.V., Lee, C., Tien, L.W., Kaplan, D.L., Feany, M., and Whalen, M. (2013). Clinical correlates in an experimental model of repetitive mild brain injury. Ann. Neurol. 74, 65-75.

89. Mouzon, B., Bachmeier, C., Ferro, A., Ojo, J.O., Crynen, G., Acker, C.M., Davies, P., Mullan, M., Stewart, W., and Crawford, F. (2014). Chronic neuropathological and neurobehavioral changes in a repetitive mild traumatic brain injury model. Ann. Neurol. 75, 241-254.

90. Bolton, A.N. and Saatman, K.E. (2014). Regional neurodegeneration and gliosis are amplified by mild traumatic brain injury repeated at 24-hour intervals. J. Neuropathol. Exp. Neurol. 73, 933-947.

91. Xu, L., Nguyen, J.V., Lehar, M., Menon, A., Rha, E., Arena, J., Ryu, J., Marsh-Armstrong, N., Marmarou, C.R., and Koliatsos, V.E. (2014). Repetitive mild traumatic brain injury with impact acceleration in the mouse: multifocal axonopathy, neuroinflammation, and neurodegeneration in the visual system. Exp. Neurol. 275, 436-449.

92. Arun, P., Abu-Taleb, R., Oguntayo, S., Tanaka, M., Wang, Y., Valiyaveettil, M., Long, J.B., Zhang, Y., and Nambiar, M.P. (2013). Distinct patterns of expression of traumatic brain injury biomarkers after blast exposure: role of compromised cell membrane integrity. Neurosci. Lett. 552, 87-91. 
93. Kane, M.J., Angoa-Pérez, M., Briggs, D.I., Viano, D.C., Kreipke, C.W., and Kuhn, D.M. (2012). A mouse model of human repetitive mild traumatic brain injury. J. Neurosci. Methods 203, 41-49.

94. Namjoshi, D.R., Cheng, W.H., McInnes, K.A., Martens, K.M., Carr, M., Wilkinson, A., Fan, J., Robert, J., Hayat, A., Cripton, P.A., and Wellington, C.L. (2014). Merging pathology with biomechanics using CHIMERA (Closed-Head Impact Model of Engineered Rotational Acceleration): a novel, surgery-free model of traumatic brain injury. Mol. Neurodegener. 9, 55.

95. Zhang, J., Teng, Z., Song, Y., Hu, M., and Chen, C. (2015). Inhibition of monoacylglycerol lipase prevents chronic traumatic encephalopathy-like neuropathology in a mouse model of repetitive mild closed head injury. J. Cereb. Blood Flow Metab. 35, 706.

96. Andorfer, C., Kress, Y., Espinoza, M., de Silva, R., Tucker, K.L., Barde, Y.A., Duff, K., and Davies, P. (2003). Hyperphosphorylation and aggregation of tau in mice expressing normal human tau isoforms. J. Neurochem. 86, 582-590.

97. Ishihara, T., Zhang, B., Higuchi, M., Yoshiyama, Y., Trojanowski, J.Q., and Lee, V.M. (2001). Age-dependent induction of congophilic neurofibrillary tau inclusions in tau transgenic mice. Am. J. Pathol. 158, 555-562.

98. Ojo, J.O., Mouzon, B., Greenberg, M.B., Bachmeier, C., Mullan, M., and Crawford, F. (2013). Repetitive mild traumatic brain injury augments tau pathology and glial activation in aged hTau mice. J. Neuropathol. Exp. Neurol. 72, 137-151.

99. Johnson, V.E., Stewart, W., and Smith, D.H. (2013). Axonal pathology in traumatic brain injury. Exp. Neurol. 246, 35-43.

100. Povlishock, J.T., and Katz, D.I. (2005). Update of neuropathology and neurological recovery after traumatic brain injury. J. Head Trauma Rehabil. 20, 76-94.

101. Johnson, V.E., Stewart, J.E., Begbie, F.D., Trojanowski, J.Q., Smith, D.H., and Stewart, W. (2013). Inflammation and white matter degeneration persist for years after a single traumatic brain injury. Brain 136, 28-42.

102. Donovan, V., Kim, C., Anugerah, A.K., Coats, J.S., Oyoyo, U., Pardo, A.C., and Obenaus, A. (2014). Repeated mild traumatic brain injury results in long-term white-matter disruption. J. Cereb Blood Flow Metab. 34, 715-723.

103. Fidan, E., Lewis, J., Kline, A.E., Garman, R.H., Alexander, H., Cheng, J.P., Bondi, C.O., Clark, R., Dezfulian, C., Kochanek, P.M., Kagan, V.E., and Bayır, H. (2016). Repetitive mild traumatic brain injury in the developing brain: effects on long-term functional outcome and neuropathology. J. Neurotrauma 33, 641-651.

104. Mierzwa, A.J., Marion, C.M., Sullivan, G.M., McDaniel, D.P., and Armstrong, R.C. (2015). Components of myelin damage and repair in the progression of white matter pathology after mild traumatic brain injury. J. Neuropathol. Exp. Neurol. 74, 218-232.

105. Sajja, V.S., Perrine, S.A., Ghoddoussi, F., Hall, C.S., Galloway, M.P., and VandeVord, P.J. (2014). Blast neurotrauma impairs working memory and disrupts prefrontal myo-inositol levels in rats. Mol. Cell. Neurosci. 59, 119-126.

106. Svetlov, S.I., Prima, V., Kirk, D.R., Gutierrez, H., Curley, K.C., Hayes, R.L., and Wang, K.K. (2010). Morphologic and biochemical characterization of brain injury in a model of controlled blast overpressure exposure. J Trauma 69, 795-804.

107. Vorhees, C.V. and Williams, M.T. (2006). Morris water maze: procedures for assessing spatial and related forms of learning and memory. Nat. Protoc. 1, 848-858.

108. Hamm, R.J., Pike, B.R., O’Dell, D.M., Lyeth, B.G., and Jenkins, L.W. (1994). The rotarod test: an evaluation of its effectiveness in assessing motor deficits following traumatic brain injury. J. Neurotrauma 11, 187-196.

109. Laurer, H.L., Bareyre, F.M., Lee, V.M., Trojanowski, J.Q., Longhi, L., Hoover, R., Saatman, K.E., Raghupathi, R., Hoshino, S., Grady, M.S., and McIntosh, T.K. (2001). Mild head injury increasing the brain's vulnerability to a second concussive impact. J. Neurosurgery 95, 859-870.

110. Meehan, W.P., 3rd, Zhang, J., Mannix, R., and Whalen, M.J. (2012). Increasing recovery time between injuries improves cognitive outcome after repetitive mild concussive brain injuries in mice. Neurosurgery $71,885-891$.

111. Petraglia, A.L., Plog, B.A., Dayawansa, S., Chen, M., Dashnaw, M.L., Czerniecka, K., Walker, C.T., Viterise, T., Hyrien, O., Iliff, J.J., Deane, R., Nedergaard, M., and Huang, J.H. (2014). The spectrum of neurobehavioral sequelae after repetitive mild traumatic brain injury: a novel mouse model of chronic traumatic encephalopathy. J. Neurotrauma 31, 1211-1224.

112. Mouzon, B., Chaytow, H., Crynen, G., Bachmeier, C., Stewart, J., Mullan, M., Stewart, W., and Crawford, F. (2012). Repetitive mild traumatic brain injury in a mouse model produces learning and memory deficits accompanied by histological changes. J. Neurotrauma 29, 2761-2773.

113. Koliatsos, V.E., Cernak, I., Xu, L., Song, Y., Savonenko, A., Crain, B.J., Eberhart, C.G., Frangakis, C.E., Melnikova, T., Kim, H., and Lee, D. (2011). A mouse model of blast injury to brain: initial pathological, neuropathological, and behavioral characterization. J. Neuropathol. Exp. Neurol. 70, 399-416.

114. Säljö, A., Bolouri, H., Mayorga, M., Svensson, B., and Hamberger, A. (2010). Low-level blast raises intracranial pressure and impairs cognitive function in rats: prophylaxis with processed cereal feed. J. Neurotrauma 27, 383-389.

115. Longhi, L., Saatman, K.E., Fujimoto, S., Raghupathi, R., Meaney, D.F., Davis, J., McMillan, A., Conte, V., Laurer, H.L., Stein, S., Stocchetti, N., and McIntosh, T.K. (2005). Temporal window of vulnerability to repetitive experimental concussive brain injury. Neurosurgery 56, 364-374.

116. Turner, R.C., Lucke-Wold, B.P., Robson, M.J., Omalu, B.I., Petraglia, A.L., and Bailes, J.E. (2013). Repetitive traumatic brain injury and development of chronic traumatic encephalopathy: a potential role for biomarkers in diagnosis, prognosis, and treatment? Front. Neurol. 3, 186.

117. Villemagne, V.L. and Okamura, N. (2014). In vivo tau imaging: obstacles and progress. Alzheimers Dement. 10, Suppl, S254-S264.

118. Barrio, J.R., Huang, S.C., Cole, G., Satyamurthy N., Petric A., Phelps M.E., and Small, G. (1999). PET imaging of tangles and plaques in Alzheimer disease with a highly hydrophobic probe. J. Labelled Compd. Radiopharm. S194-S195.

119. Maruyama, M., Shimada, H., Suhara, T., Shinotoh, H., Ji, B., Maeda, J., Zhang, M.R., Trojanowski, J.Q., Lee, V.M., Ono, M., Masamoto, K., Takano, H., Sahara, N., Iwata, N., Okamura, N., Furumoto, S., Kudo, Y., Chang, Q., Saido, T.C., Takashima, A., Lewis, J., Jang, M.K., Aoki, I., Ito, H., and Higuchi, M. (2013). Imaging of tau pathology in a tauopathy mouse model and in Alzheimer patients compared to normal controls. Neuron 79, 1094-1108.

120. National Institute of Mental Health. (2015). PET imaging in chronic traumatic encephalopathy. National Library of Medicine (US): Bethesda, MD. Available at: clinicaltrials.gov/ct2/show/NCT02211820 Accessed September 4, 2017.

121. Chien, D.T., Bahri, S., Szardenings, A.K., Walsh, J.C., Mu, F., Su, M.Y., Shankle, W.R., Elizarov, A., and Kolb, H.C. (2013). Early clinical PET imaging results with the novel PHF-tau radioligand [F18]-T807. J. Alzheimers Dis. 34, 457-468.

122. Chien, D.T., Szardenings, A.K., Bahri, S., Walsh, J.C., Mu, F., Xia, C., Shankle, W.R., Lerner, A.J., Su, M.Y., Elizarov, A., and Kolb, H.C. (2014). Early clinical PET imaging results with the novel PHFtau radioligand [F18]-T808. J. Alzheimers Dis. 38, 171-184.

123. Avid Radiopharmaceuticals. (2015). 18F-AV-1451 and Florbetapir F 18 PET imaging in subjects at risk for chronic traumatic encephalopathy. Available at: clinicaltrials.gov/ct2/show/NCT02016560. Accessed September 4, 2017.

124. Di Carli, M. (2015). Tau imaging of chronic traumatic encephalopathy. Available at: clinicaltrials.gov/ct2/show/NCT02191267. Accessed September 4, 2017.

125. Villemagne, V.L., Fodero-Tavoletti, M.T., Masters, C.L., and Rowe, C.C. (2015). Tau imaging: early progress and future directions. Lancet Neurol. 14, 114-124.

126. Shah, M. and Catafau, A.M. (2014). Molecular imaging insights into neurodegeneration: focus on tau PET radiotracers. J. Nucl. Med. 55, 871-874.

127. Smid, L.M., Kepe, V., Vinters, H.V., Bresjanac, M., Toyokuni, T., Satyamurthy, N., Wong, K.P., Huang, S.C., Silverman, D.H., Miller, K., Small, G.W., and Barrio, J.R. (2013). Postmortem 3-D brain hemisphere cortical tau and amyloid- $\beta$ pathology mapping and quantification as a validation method of neuropathology imaging. J. Alzheimers Dis. 36, 261-274.

128. Small, G.W., Kepe, V., Siddarth, P., Ercoli, L.M., Merrill, D.A., Donoghue, N., Bookheimer, S.Y., Martinez, J., Omalu, B., Bailes, J., and Barrio, J.R. (2013). PET scanning of brain tau in retired national football league players: preliminary findings. Am. J. Geriatr. Psychiatry $21,138-144$. 
129. Barrio, J., Small, G.W., Wong, K.P., Huang, S.C., Liu, J., Merrill, D.A., Giza, C.C., Fitzsimmons, R.P., Omalu, B., Bailes, J., and Kepe, V. (2015). In vivo characterization of chronic traumatic encephalopathy using [F-18]FDDNP PET brain imaging. Proc. Natl. Acad. Sci. U. S. A. 112, E2039-E2047.

130. Shoghi-Jadid, K., Small, G.W., Agdeppa, E.D., Kepe, V., Ercoli, L.M., Siddarth, P., Read, S., Satyamurthy, N., Petric, A., Huang, S.C., and Barrio, J.R. (2002). Localization of neurofibrillary tangles and beta-amyloid plaques in the brains of living patients with Alzheimer disease. Am. J. Geriatr. Psychiatry 10, 24-35.

131. Nelson, L., Siddarth, P., Kepe, V., Scheibel KE, Huang SC, Barrio JR, and Small GW. (2011). Positron emission tomography of brain $\beta$ amyloid and tau levels in adults with Down syndrome. Arch. Neurol. 68, 768-774.

132. Provenzano, F.A., Jordan, B., Tikofsky, R.S., Saxena, C., Van Heertum, R.L., and Ichise, M. (2010). F-18 FDG PET imaging of chronic traumatic brain injury in boxers: a statistical parametric analysis. Nucl. Med. Commun. 31, 952-957.

133. Bonte, F.J., Harris, T.S., Roney, C.A., and Hynan, L.S. (2004). Differential diagnosis between Alzheimer's and frontotemporal disease by the posterior cingulate sign. J. Nucl. Med. 45, 771-774.

134. Segobin, S., La Joie, R., Ritz, L., Beaunieux, H., Desgranges, B., Chetelat, G., Pitel, A.L., and Eustache, F. (2015). FDG-PET contributions to the pathophysiology of memory impairment. Neuropsychol. Rev. 25, 326-355.

135. Folkersma, H., Boellaard, R., Yaqub, M., Kloet, R.W., Windhorst, A.D., Lammertsma, A.A., Vandertop, W.P., and van Berckel, B.N. (2011). Widespread and prolonged increase in (R)-(11)C-PK11195 binding after traumatic brain injury. J. Nucl. Med. 52, 1235-1239.

136. Ramlackhansingh, A.F., Brooks, D.J., Greenwood, R.J., Bose, S.K., Turkheimer, F.E., Kinnunen, K.M., Gentleman, S., Heckemann, R.A., Gunanayagam, K., Gelosa, G., and Sharp, D.J. (2011). Inflammation after trauma: microglial activation and traumatic brain injury. Ann. Neurol. 70, 374-383.

137. Coughlin, J.M., Wang, Y., Munro, C.A., Ma, S., Yue, C., Chen, S., Airan, R., Kim, P.K., Adams, A.V., Garcia, C., Higgs, C., Sair, H.I., Sawa, A., Smith, G., Lyketsos, C.G., Caffo, B., Kassiou, M., Guilarte, T.R., and Pomper, M.G. (2015). Neuroinflammation and brain atrophy in former NFL players: an in vivo multimodal imaging pilot study. Neurobiol. Dis. 74, 58-65.

138. Bazarian, J.J., Zhu, T., Blyth, B., Borrino, A., and Zhong, J. (2012). Subject-specific changes in brain white matter on diffusion tensor imaging after sports-related concussion. Magn. Reson. Imaging 30, $171-180$.

139. Bazarian, J.J., Zhu, T., Zhong, J., Janigro, D., Rozen, E., Roberts, A., Javien, H., Merchant-Borna, K., Abar, B., and Blackman, E.G. (2014). Persistent, long-term cerebral white matter changes after sports-related repetitive head impacts. PLoS One 9, e94734.

140. Lipton, M.L., Gulko, E., Zimmerman, M.E., Friedman, B.W., Kim, M., Gellella, E., Gold, T., Shifteh, K., Ardekani, B.A., and Branch, C.A. (2009). Diffusion-tensor imaging implicates prefrontal axonal injury in executive function impairment following very mild traumatic brain injury. Radiology 252, 816-824.

141. Strain, J., Didehbani, N., Cullum, M., Mansinghani, S., Conover, H., Kraut, M.A., Hart, J.J., Jr., and Womack, K.B. (2013). Depressive symptoms and white matter dysfunction in retired NFL players with concussion history. Neurology 81, 25-32.

142. Hart, J.J., Jr., Kraut, M.A., Womack, K.B., Strain, J., Didehbani, N., Bartz, E., Conover, H., Mansinghani, S., Lu, H., and Cullum, M. (2013). Neuroimaging of cognitive dysfunction and depression in aging retired National Football League players: a cross-sectional study. JAMA Neurol. 70, 326-335.

143. Davenport, N.D., Lim, K.O., Armstrong, M.T., and Sponheim, S.R. (2012). Diffuse and spatially variable white matter disruptions are associated with blast-related mild traumatic brain injury. Neuroimage 59, 2017-2024.

144. Hayes, J.P., Miller, D.R., Lafleche, G., Salat, D.H., and Verfaellie, M. (2015). The nature of white matter abnormalities in blast-related mild traumatic brain injury. Neuroimage Clin. 8, 148-156.

145. Morey, R.A., Haswell, C.C., Selgrade, E.S., Massoglia, D., Liu, C., Weiner, J., Marx, C.E.; MIRECC Work Group, Cernak, I., and McCarthy, G. (2013). Effects of chronic mild traumatic brain injury on white matter integrity in Iraq and Afghanistan war veterans. Hum. Brain Mapp. 34, 2986-2999.
146. Petrie, E.C., Cross, D.J., Yarnykh, V.L., Richards, T., Martin, N.M., Pagulayan, K., Hoff, D., Hart, K., Mayer, C., Tarabochia, M., Raskind, M.A., Minoshima, S., and Peskind, E.R. (2014). Neuroimaging, behavioral, and psychological sequelae of repetitive combined blast/ impact mild traumatic brain injury in Iraq and Afghanistan war veterans. J. Neurotrauma 31, 425-436.

147. Mac Donald, C., Johnson, A., Cooper, D., Malone, T., Sorrell, J., Shimony, J., Parsons, M., Snyder, A., Raichle, M., Fang, R., Flaherty, S., Russell, M., and Brody, D.L. (2013). Cerebellar white matter abnormalities following primary blast injury in US military personnel. PLoS One 8, e55823.

148. Jorge, R.E., Acion, L., White, T., Tordesillas-Gutierrez, D., Pierson, R., Crespo-Facorro, B., and Magnotta, V.A. (2012). White matter abnormalities in veterans with mild traumatic brain injury. Am J Psychiatry 169, 1284-1291.

149. Levin, H., Wilde, E., Troyanskaya, M., Petersen, N.J., Scheibel, R., Newsome, M., Radaideh, M., Wu, T., Yallampalli, R., Chu, Z., and $\mathrm{Li}, \mathrm{X}$. (2010). Diffusion tensor imaging of mild to moderate blastrelated traumatic brain injury and its sequelae. J. Neurotrauma 27 , 683-694.

150. Gavett, B.E., Cantu, R.C., Shenton, M., Lin, A.P., Nowinski, C.J., McKee, A.C., and Stern, R.A. (2011). Clinical appraisal of chronic traumatic encephalopathy: current perspectives and future directions. Curr. Opin. Neurol. 24, 525-531.

151. Henry, L.C., Tremblay, S., Boulanger, Y., Ellemberg, D., and Lassonde, M. (2010). Neurometabolic changes in the acute phase after sports concussions correlate with symptom severity. J. Neurotrauma 27, 65-76.

152. Lin, A., Ramadan, S., Box, H., Stanwell, P., Stern, R., and Mountford, C. (2010). Neurochemical Changes in Athletes with Chronic Traumatic Encephalopathy. Radiological Society of North America: Chicago, IL.

153. Lin, A., Ramadan, S., Stern, R.A., Box, H.C., Nowinski, C.J., Ross, B.D., and Mountford, C.E. (2015). Changes in the neurochemistry of athletes with repetitive brain trauma: preliminary results using localized correlated spectroscopy. Alzheimers Res. Ther. 7, 13.

154. Tremblay, S., De Beaumont, L., Henry, L.C., Boulanger, Y., Evans, A.C., Bourgouin, P., Poirier, J., Théoret, H., and Lassonde, M. (2013). Sports concussions and aging: a neuroimaging investigation. Cereb. Cortex 23, 1159-1166.

155. Signoretti, S., Marmarou, A., Aygok, G.A., Fatouros, P.P., Portella, G., and Bullock, R.M. (2008). Assessment of mitochondrial impairment in traumatic brain injury using high-resolution proton magnetic resonance spectroscopy. J Neurosurg 108, 42-52.

156. de Lanerolle, N.C., Hamid, H., Kulas, J., Pan, J.W., Czlapinski, R., Rinaldi, A., Ling, G., Bandak, F.A., and Hetherington, H.P. (2014). Concussive brain injury from explosive blast. Ann Clin Transl Neurol 1, 692-702.

157. Hetherington, H.P., Hamid, H., Kulas, J., Ling, G., Bandak, F., de Lanerolle, N.C., and Pan, J.W. (2014). MRSI of the medial temporal lobe at $7 \mathrm{~T}$ in explosive blast mild traumatic brain injury. Magn Reson Med 71, 1358-1367.

158. Bruce, E.D., Konda, S., Dean, D.D., Wang, E.W., Huang, J.H., and Little, D.M. (2015). Neuroimaging and traumatic brain injury: state of the field and voids in translational knowledge. Mol Cell Neurosci $66,103-113$.

159. Gandy, S., Ikonomovic, M.D., Mitsis, E., Elder, G., Ahlers, S.T., Barth, J., Stone, J.R., and DeKosky, S.T. (2014). Chronic traumatic encephalopathy: clinical-biomarker correlations and current concepts in pathogenesis. Mol Neurodegener 9, 37.

160. Strain, J.F., Womack, K.B., Didehbani, N., Spence, J.S., Conover, H., Hart, J.J., Kraut, M.A., and Cullum, M. (2015). Imaging correlates of memory and concussion history in retired National Football League athletes. JAMA Neurol 72, 773-780.

161. Talavage, T.M., Nauman, E.A., Breedlove, E.L., Yoruk, U., Dye, A.E., Morigaki, K.E., Feuer, H., and Leverenz, L.J. (2010). Functionally-detected cognitive impairment in high school football players without clinically-diagnosed concussion. J Neurotrauma 31, 327-338.

162. Baugh, C.M., Stamm, J.M., Riley, D.O., Gavett, B.E., Shenton, M.E., Lin, A., Nowinski, C.J., Cantu, R.C., McKee, A.C., and Stern, R.A. (2012). Chronic traumatic encephalopathy: neurodegeneration following repetitive concussive and subconcussive brain trauma. Brain Imaging Behav 6, 244-254. 
163. Mez, J., Stern, R.A., and McKee, A.C. (2013). Chronic traumatic encephalopathy: where are we and where are we going? Curr Neurol Neurosci Rep 13, 407.

164. DeKosky, S.T., Blennow, K., Ikonomovic, M.D., and Gandy, S. (2013). Acute and chronic traumatic encephalopathies: pathogenesis and biomarkers. Nat Rev Neurol 9, 192-200.

165. Zetterberg, H., and Blennow, K. (2015). Fluid markers of traumatic brain injury. Mol Cell Neurosci 66, 99-012.

166. Neselius, S., Brisby, H., Theodorsson, A., Blennow, K., Zetterberg, H., and Marcusson, J. (2012). CSF-biomarkers in olympic boxing: diagnosis and effects of repetitive head trauma. PLoS ONE 7, e33606.

167. Neselius, S., Zetterberg, H., Blennow, K., Randall, J., Wilson, D., Marcusson, J., and Brisby, H. (2013). Olympic boxing is associated with elevated levels of the neuronal protein tau in plasma. Brain Inj. $27,425-433$.

168. Zetterberg, H., Hietala, M., Jonsson, M., Andreasen N, Styrud E, Karlsson I, Edman A, Popa C, Rasulzada A, Wahlund LO, Mehta PD, Rosengren L, Blennow K, and Wallin A. (2006). Neurochemical aftermath of amateur boxing. Arch. Neurol. 63, 1277-1280.

169. Anderson, R.E., Hansson, L.O., Nilsson, O., Dijlai-Merzoug, R., and Settergren, G. (2001). High serum S100B levels for trauma patients without head injuries. Neurosurgery 48, 1255-1258.

170. Naeimi, Z.S., Weinhofer, A., Sarahrudi, K., Heinz, T., and Vécsei, V. (2006). Predictive value of S-100B protein and neuron specificenolase as markers of traumatic brain damage in clinical use. Brain Inj. 20, 463-468.

171. Mondello, S., Jeromin, A., Buki, A., Bullock, R., Czeiter, E., Kovacs, N., Barzo, P., Schmid, K., Tortella, F., Wang, K.K., and Hayes, R.L. (2012). Glial neuronal ratio: a novel index for differentiating injury type in patients with severe traumatic brain injury. J. Neurotrauma 29, 1096-1104.

172. Olivera, A., Lejbman, N., Jeromin, A., French, L.M., Kim, H.S., Cashion, A., Mysliwiec, V., Diaz-Arrastia, R., and Gill, J. (2015). Peripheral total tau in military personnel who sustain traumatic brain injuries during deployment. JAMA Neurol. 72, 1109-1116.

173. Zetterberg, H., Tanriverdi, F., Unluhizarci, K., Selcuklu, A., Kelestimur, F., and Blennow, K. (2009). Sustained release of neuronspecific enolase to serum in amateur boxers. Brain Inj. 23, 723-726.

174. Green, R.E., Colella, B., Maller, J.J., Bayley, M., Glazer, J., and Mikulis, D.J. (2014). Scale and pattern of atrophy in the chronic early stages of moderate-severe TBI. Front Hum Neurosci 8, 67.

175. Ng, K., Mikulis, D.J., Glazer, J., Kabani, N., Till, C., Greenberg, G., Thompson, A., Lazinski, D., Agid, R., Colella, B., and Green, R.E. (2008). Magnetic resonance imaging evidence of progression of subacute brain atrophy in moderate to severe traumatic brain injury. Arch Phys Med Rehabil 89 Suppl 2, S35-S44.

176. Farbota, K.D., Sodhi, A., Bendlin, B.B., McLaren, D.G., Xu, G., Rowley, H.A., and Johnson, S.C. (2012). Longitudinal volumetric changes following traumatic brain injury: a tensor based morphometry study. J Int Neuropsychol Soc 18, 1006-1018.

177. Bendlin, B., Ries, M.L., Lazar, M., Alexander, A.L., Dempsey, R.J., Rowley, H.A., Sherman, J.E., and Johnson, S.C. (2008). Longitudinal changes in patients with traumatic brain injury assessed with diffusion tensor and volumetric imaging. Neuroimage 42, 503-514.

178. Farbota, K.D., Bendlin, B.B., Alexander, A.L., Rowley, H.A., Dempsey, R.J., and Johnson, S.C. (2012). Longitudinal diffusion tensor imaging and neuropsychological correlates in traumatic brain injury patients. Front Hum Neurosci 6, 160.

179. Johnson, V.E., Stewart, W., and Smith, D.H. (2012). Widespread tau and amyloid-beta pathology many years after a single traumatic brain injury in humans. Brain Pathol. 22, 142-149.

180. Till, C., Colella, B., Verwegen, J., and Green, R.E. (2008). Postrecovery cognitive decline in adults with traumatic brain injury. Arch. Phys. Med. Rehabil. 89, Suppl 2, S25-S34.

181. Ryu, J., Horkayne-Szakaly, I., Xu, L., Pletnikova, O., Leri, F., Eberhart, C., Troncoso, J.C., and Koliatsos, V.E. (2014). The prob- lem of axonal injury in the brains of veterans with histories of blast exposure. Acta Neuropathol. Commun. 2, 153.

182. Turner, R.C., Lucke-Wold, B.P., Logsdon, A.F., Robson, M.J., Dashnaw, M.L., Huang, J.H., Smith, K.E., Huber, J.D., Rosen, C.L., and Petraglia, A.L. (2015). The quest to model chronic traumatic encephalopathy: a multiple platform model and injury paradigm experience. Front. Neurol. 6, 222.

183. Huber, B.R., Meabon, J.S., Martin, T.J., Mourad, P.D., Bennett, R., Kraemer, B.C., Cernak, I., Petrie, E.C., Emery, M.J., Swenson, E.R., Mayer, C., Mehic, E., Peskind, E.R., and Cook, D.G. (2013). Blast exposure causes early and persistent aberrant phospho- and cleavedtau expression in a murine model of mild blast-induced traumatic brain injury. J. Alzheimers Dis. 37, 309-323.

184. Harmon, K.G., Drezner, J.A., Gammons, M., Guskiewicz, K.M., Halstead, M., Herring, S.A., Kutcher, J.S., Pana, A., Putukian, M., and Roberts, W.O. (2013). American Medical Society for Sports Medicine position statement: concussion in sport. Br J Sports Med 47, 15-26.

185. McCrory, P., Meeuwisse, W.H., Aubry, M., Cantu, R.C., Dvořák, J., Echemendia, R.J., Engebretsen, L., Johnston, K., Kutcher, J.S., Raftery, M., Sills, A., Benson, B.W., Davis, G.A., Ellenbogen, R., Guskiewicz, K.M., Herring, S.A., Iverson, G.L., Jordan, B.D., Kissick, J., McCrea, M., McIntosh, A.S., Maddocks, D., Makdissi, M. Purcell, L., Putukian, M., Schneider, K., Tator, C.H., and Turner, M. (2013). Consensus statement on concussion in sport: the 4th International Conference on Concussion in Sport, Zurich, November 2012. J. Athl. Train. 48, 554-575.

186. Herring, S.A., Cantu, R.C., Guskiewicz, K.M., Putukian, M., Kibler, W.B., Bergfeld, J.A., Boyajian-O'Neill, L.A., Franks, R.R., Indelicato, P.A., and American College of Sports Medicine. (2011) Concussion (mild traumatic brain injury) and the team physician: a consensus statement-2011 update. Med. Sci. Sports Exerc. 43, 2412-2422.

187. McCulloch, K.L., Goldman, S., Lowe, L., Radomski, M.V., Reynolds, J., Shapiro, R., and West, T.A. (2015). Development of clinical recommendations for progressive return to activity after military mild traumatic brain injury: guidance for rehabilitation providers. J. Head Trauma Rehabil. 30, 56-67.

188. Kondo, A., Shahpasand, K., Mannix, R., Qiu, J., Moncaster, J., Chen, C.H., Yao, Y., Lin, Y.M., Driver, J.A., Sun, Y., Wei, S., Luo, M.L., Albayram, O., Huang, P., Rotenberg, A., Ryo, A., Goldstein, L.E., Pascual-Leone, A., McKee, A.C., Meehan, W., Zhou, X.Z., and Lu, K.P. (2015). Antibody against early driver of neurodegeneration cis P-tau blocks brain injury and tauopathy. Nature 523, 431-436.

189. Cook, C., Carlomagno, Y., Gendron, T.F., Dunmore, J., Scheffel, K., Stetler, C., Davis, M., Dickson, D., Jarpe, M., DeTure, M., and Petrucelli, L. (2014). Acetylation of the KXGS motifs in tau is a critical determinant in modulation of tau aggregation and clearance. Hum Mol Genet 23, 104-116.

190. Cook, C., Stankowski, J.N., Carlomagno, Y., Stetler, C., and Petrucelli, L. (2014). Acetylation: a new key to unlock tau's role in neurodegeneration. Alzheimers Res. Ther. 6, 29.

191. Levin, B., and Bhardwaj, A. (2014). Chronic traumatic encephalopathy: a critical appraisal. Neurocrit. Care 20, 334-344.

Address correspondence to: Raj K. Gupta, PhD

Department of Defense Blast Injury Research Program Coordinating Office

United States Army Medical Research and Materiel Command 504 Scott Street

Fort Detrick, MD 21702

E-mail: raj.k.gupta.civ@mail.mil 